\title{
Quench sensitivity of Al-Mg-Si alloys: A model for linear cooling and strengthening
}

\author{
B. Milkereit ${ }^{1,2,3,{ }^{*}, \text { M.J. Starink }}{ }^{1}$
}

\section{benjamin.milkereit@uni-rostock.de; M.J.Starink@soton.ac.uk}

${ }^{1}$ Materials Research Group, Engineering Sciences, University of Southampton, S017 1BJ Southampton

${ }^{2}$ Chair of Materials Science, Faculty of Marine Technology and Mechanical Engineering, University of Rostock, 18051 Rostock

${ }^{3}$ Polymer Physics Group, Institute of Physics, University of Rostock, 18051 Rostock

*corresponding author: Telephone: 0049-381-498-9486; Fax: 0049-381-498-9472

\section{Abstract}

This work studies the quench-induced precipitation during continuous cooling of five Al-Mg-Si alloys over a wide range of cooling rates of $0.05-2 \cdot 10^{4} \mathrm{~K} / \mathrm{min}$ using Differential Scanning Calorimetry (DSC), X-ray diffraction, optical- (OM), transmission electron- (TEM) and scanning electron microscopy (SEM) plus hardness testing. The DSC data shows that the cooling reactions are dominated by a high temperature reaction (typically $500^{\circ} \mathrm{C}$ down to $380^{\circ} \mathrm{C}$ ) and a lower temperature reaction $\left(380^{\circ} \mathrm{C}\right.$ down to $250^{\circ} \mathrm{C}$ ), and the microstructural analysis shows they are $\beta-\mathrm{Mg}_{2} \mathrm{Si}$ phase formation and $\mathrm{B}$ ' phase precipitation, respectively. A new, physically-based model is designed to model the precipitation during the quenching as well as the strength after cooling and after subsequent age hardening. After fitting of parameters, the highly efficient model allows to predict accurately the measured quench sensitivity, the volume fractions of quench induced precipitates, enthalpy changes in the quenched sample and hardness values. Thereby the model can be used to optimise alloy and/or process design by exploiting the full age hardening potential of the alloys choosing the appropriate alloy composition and/ or cooling process. Moreover, the model can be implemented in FEM tools to predict the mechanical properties of complex parts after cooling. 


\section{Keywords}

Al-Mg-Si alloys; quench sensitivity; Differential Scanning Calorimetry (DSC); precipitation kinetics; Modelling

\section{Introduction}

In recent years substantial progress has been reported in modelling of diffusion controlled phase transformations and the modelling of the thermodynamics of commercially important complex alloy systems, including first principles modelling. In this paper we will investigate how this progress can be used to provide a computationally efficient new model for a technically important process: quench sensitivity of heat treatable aluminium alloys. In heat treatable Al-based alloys precipitation hardening is the dominant strengthening mechanism. For most commonly used alloys such as the Al-Mg-Si (6xxx) and the Al-Zn-Mg-(Cu) (7xxx) alloys, age hardening response can be seriously affected by the cooling rate from solution annealing (e. g. [1-9]; and also toughness can be reduced due to reduced cooling rate [10]. To achieve optimal mechanical properties, precipitation during quenching must be fully suppressed, and this is achieved only if the alloy is cooled with the upper critical cooling rate or faster (e. g. $[4,8,7])$. However, fast cooling can induce residual stresses (e. g. [11-13]), and hence, in order to obtain an optimal balance between strength and residual stresses / distortion, cooling from solution annealing should be done with the upper critical cooling rate or slightly faster. Nevertheless, in some parts with varying wall dimensions it might be difficult to realise the same cooling rate at every location. Nowadays it is relatively easy to calculate the temperature developments in such parts at every location by finite element modelling (e. g. [12]). However, for prediction of the mechanical properties at varying cooling rates, no models that incorporate reliable thermodynamic and kinetic models have hitherto been published, nor have any models been tested using extensive experimental data. The present work addresses these issues in two ways: improved models and model verification through comparison with much increased and more detailed experimental results. 
Differential Scanning Calorimetry (DSC) is frequently used for investigation of diffusion-controlled precipitation reactions (e.g. [14,3,15,8,16,17]). In recent years significant improvements were obtained in the in situ investigation of the precipitation processes during cooling of Al alloys from solution annealing through the development of high sensitivity in-situ DSC techniques [18-21]. These technically and metrological sound DSC methods allow to measure the enthalpy changes over the whole cooling rate range of technical and scientific interest: from slow cooling with phase transformation close to equilibrium conditions up to cooling rates near the upper critical cooling rate. In the present work, the enthalpy change during cooling is used as basis for the modelling.

We will in this work derive a model for precipitation during quenching and subsequent ageing of AlMg-Si alloys and combine that with a model for precipitation hardening, to provide predictions of strength and hardness for cooling rates that stretch over 6 decades. In the model we will incorporate very recent progress in first principles modelling of the phases in the Al-Mg-Si system results [22] and very recent models for precipitation kinetics [23,24]. The model is tested against an extensive set of experimental data.

\section{Experimental}

\subsection{Investigated alloys}

In this work, five different 6xxx alloys covering a wide range of compositions were investigated. The alloys are AA6063, AA6005A, and three alloys within the composition range of AA6082, representing variants with low Mg and Si content (AA6082 low), typical (medium) Mg and Si content (AA6082typ) and

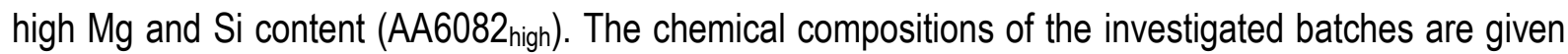
in Table 1. All alloys have been cast, homogenised and subsequently extruded. They were received as extruded profiles, from which samples were cut for further heat treatment and investigations. We combine a very large amount of new and existing experimental data (about 600 DSC experiments, about 500 hardness tests, microstructural analysis of more than 100 samples). 
Table 1: Chemical composition of investigated alloys (mass fractions in \%) obtained by optical emission spectroscopy (OES) analysis, with experiments performed. $\mathrm{CDSC}=$ cooling DSC, hDSC = heating DSC

\begin{tabular}{|c|c|c|c|c|c|c|c|c|c|}
\hline Alloys & $\mathrm{Si}$ & $\mathrm{Fe}$ & $\mathrm{Cu}$ & $\mathrm{Mn}$ & $\mathrm{Mg}$ & $\mathrm{Cr}$ & $\mathrm{Zn}$ & $\mathrm{Ti}$ & Experiments \\
\hline AA6063 & 0.5 & 0.19 & 0.02 & 0.03 & 0.47 & 0.005 & 0.03 & 0.013 & $\begin{array}{l}\text { TEM, CDSC, SEM, HV, } \\
\text { OM, XRD }\end{array}$ \\
\hline AA6005A & 0.68 & 0.2 & 0.01 & 0.11 & 0.57 & 0.04 & 0.01 & 0.018 & $\begin{array}{l}\text { TEM, CDSC, SEM, HV, } \\
\text { OM, XRD }\end{array}$ \\
\hline AA6082 low & 0.73 & 0.22 & 0.05 & 0.48 & 0.61 & 0.003 & 0.009 & 0.02 & cDSC, SEM, HV, OM, XRD \\
\hline AA6082 typ & 1.01 & 0.19 & 0.03 & 0.44 & 0.68 & 0.04 & 0.02 & 0.01 & TEM, hDSC, HV \\
\hline AA6082 high & 1.23 & 0.2 & 0.09 & 0.65 & 1.05 & 0.2 & 0.05 & 0.03 & CDSC, SEM, HV, OM, XRD \\
\hline
\end{tabular}

\subsection{Heat treatment, Differential Scanning Calorimetry and Hardness Testing}

The main focus of this work is the quenching step within the age hardening heat treatment procedure. The basic scheme of the experimental applied heat treatments is shown Fig. 1. The solution annealing at $540{ }^{\circ} \mathrm{C}$ for 20 min was followed by linear cooling with cooling rates varying in a wide range $\left(0.05 \mathrm{~K} / \mathrm{min}-2 \cdot 10^{4} \mathrm{~K} / \mathrm{min}\right)$. Differential Scanning Calorimetry (DSC), covering cooling rates from $0.1 \mathrm{~K} / \mathrm{min}$ to $375 \mathrm{~K} / \mathrm{min}$, are realised by employing three different types of DSC devices: Setaram 121 DSC 0.1-6 K/min; Mettler-Toledo 823 DSC 6-30 K/min; PerkinElmer Pyris 1 DSC 30-375 K/min. Samples were measured versus a thermodynamic inert reference sample of pure aluminium. The baseline measurements were performed measuring pure Al samples in both DSC-microfurnaces. For
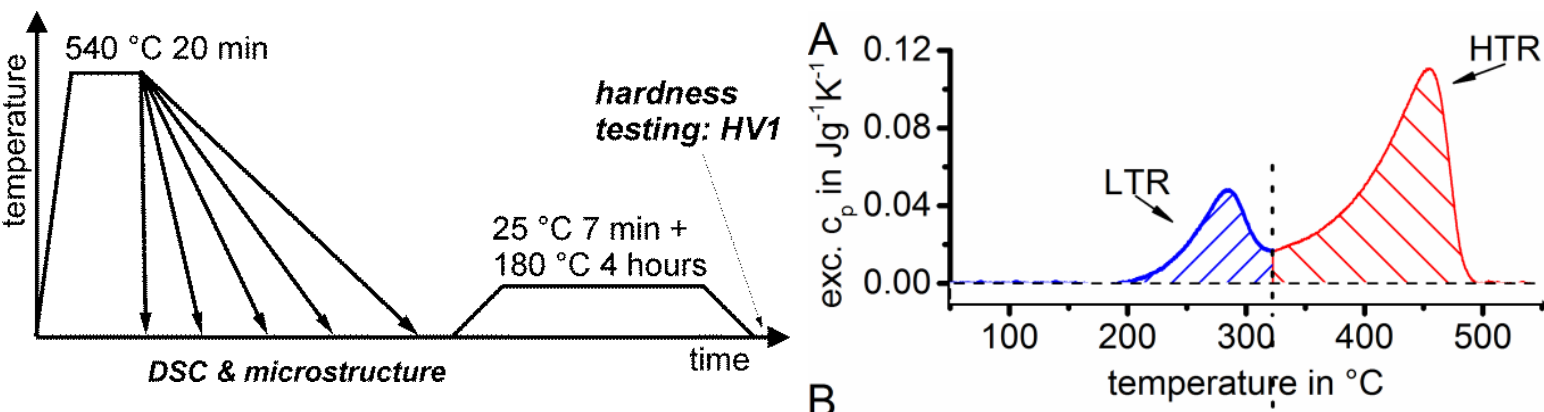

Fig. 1: Temperature-Time scheme of experiments.

Fig. 2: Schematic evaluation of DSC cooling curves by sections wise integration. (A) DSC curve separated in high- and lowtemperature-reactions (HTR / LTR). (B) Related integral curves for corresponding temperature intervals.

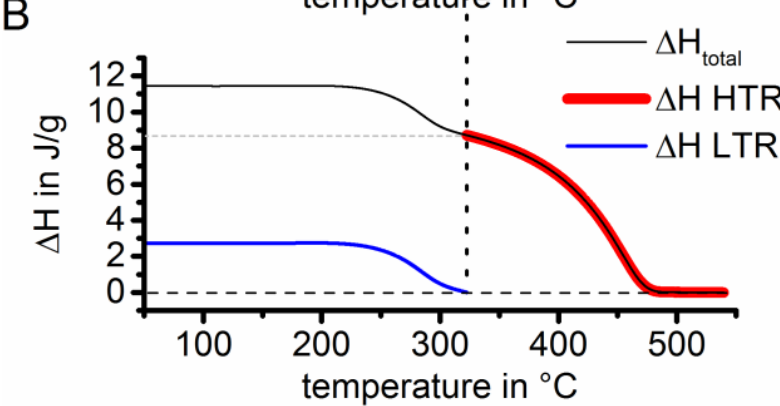


each measurement one corresponding baseline was measured, and excess specific heat capacity curves reflecting the enthalpy changes due to reactions were determined (Fig. 2A). The specific precipitation enthalpy was evaluated by integrating the excess specific heat capacity curves and precipitation enthalpies of partially overlapping precipitation peaks was evaluated using the minimum heat flow as indicated in Fig. 2B (for further details see [18]).

Samples for hardness testing were cooled to room temperature at constant rates of $0.05 \mathrm{~K} / \mathrm{min}-$ $2 \cdot 10^{4} \mathrm{~K} / \mathrm{min}$, and, following a brief $7 \mathrm{~min}$ ageing at room temperature, they were artificial aged at $180^{\circ} \mathrm{C}$ for 4 hours.

To achieve very high controlled cooling rates up to $2 \cdot 10^{4} \mathrm{~K} / \mathrm{min}$, heat treatments of additional samples were performed in a Baehr A/D 805 dilatometer. The complete heat treatments of hardness samples were performed either in DSC or dilatometer, thus ensuring a complete control of the entire temperature-time profile. Vickers hardness HV1 (load $1 \mathrm{~kg}$ ) was tested with a Shimadzu HMV-2E smallforce hardness indenter according to ISO 6507-1 applying an indentation duration of $10 \mathrm{~s}$. At least six indentations per sample were performed. In addition, selected samples for microstructure investigation on AA6082typ were solution annealed and subsequently cooled using procedures approximating industrial practice: quenching in room-temperature-water, cooling in slightly moving air and slow aircooling (in still air). Cooling rates were measured, and at $370{ }^{\circ} \mathrm{C}$ the cooling rates were about 400,3 and $1 \mathrm{~K} / \mathrm{min}$, respectively. These samples were all artificially aged after cooling (i.e. a T6 treatment) and prior to microstructure investigation.

\subsection{Microstructure analysis}

The microstructures of an extensive number of samples from 5 alloys were investigated through optical light microscopy (OM), scanning electron microscopy (SEM), transmission electron microscopy (TEM) and X-ray diffraction (XRD). In this work we present selected, representative results, focussing on the nucleation mechanisms of different quench induced phases as well as on the volume fraction of coarse quench-induced precipitates. Selected SEM and TEM data on one of the alloys was presented previously [7]. 


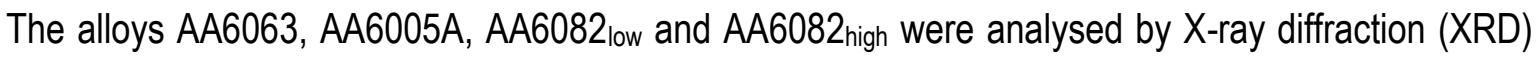
in a Siemens D5000 X-Ray Diffractometer after very slow cooling with $0.05 \mathrm{~K} / \mathrm{min}$. Cu-Ka radiation (wavelength $0.15406 \mathrm{~nm}$ ), prime-aperture gap of $2 \mathrm{~mm}$ and a measuring duration of 3.2 to $3.7 \mathrm{~s}$ per angle step were used. The angle-step-width was selected as $0.02^{\circ}$.

Samples for OM and SEM were prepared by standard grinding and polishing procedures. Ethanol based lubricants were used. Selected specimens were etched for $20 \mathrm{~s}$ in a solution of $4 \mathrm{~g}$ potassium permanganate in $100 \mathrm{ml}$ distilled $\mathrm{H}_{2} \mathrm{O}$ and $1 \mathrm{~g} \mathrm{NaHO}$. After etching an etch-skin remained on the surface, which was removed by careful polishing. As OM a Leica DMI 500 and for SEM a Zeiss SUPRA 25 (operated at $10 \mathrm{kV}$ ) were used. TEM foils were obtained by twin-jet electro-polishing (using $25 \%$ nitric acid in methanol at about $-30{ }^{\circ} \mathrm{C}$ and a voltage of $25 \mathrm{~V}$ ). Samples were investigated in a Philips CM30 and a JEOL 2000FX TEM, both operated at $300 \mathrm{kV}$. Structure analysis of selected quench induced phases was performed in SEM with electron backscatter diffraction (EBSD) and in TEM with selected area electron diffraction (SAED). For details of those analyses see $[25,7]$.

The volume fraction of coarse phases formed during cooling was obtained through analysis of OM images using the image analysis software by "dhs-Bilddatenbank", determining the area fractions of coarse phases (see e.g. [26]). For each investigated condition six OM micrographs with low magnification (200x) of polished samples were evaluated. This results in an evaluated area of about $240,000 \mu \mathrm{m}^{2}$ per condition. A minimum grey-scale level is adjusted to obtain areas of quench induced particles. The accuracy of this measurement is estimated to be about $0.1 \mathrm{vol} \%$. Beside quench induced precipitates, a certain amount of coarse Al-Fe-Si-Mn phases are visible in the evaluated OM micrographs. Those phases are formed directly from the melt in a eutectic reaction, and they possess a very similar contrast compared to $\mathrm{Mg}_{2} \mathrm{Si}$ (compare differences between those types of precipitates in OM and SEM micrographs in Fig. 6 in section 2.3). When cooling was performed overcritically fast, no quench-induced precipitates are present, and the determined volume fractions in those conditions possess a certain stable level and can directly be related to the fraction of coarse eutectic Al-Fe-Si-Mn precipitates. This constant level fraction may therefore be subtracted from the overall determined 
volume fractions in order to obtain the volume fraction of $\mathrm{Mg}_{2} \mathrm{Si}$. In line with this, the amounts of these coarse eutectic Al-Fe-Si-Mn phases are consistent with Scheil Model calculations of solidification.

\section{DSC cooling curves and microstructure of selected quench states}

\subsection{DSC cooling curves}

Fig. 3 displays selected DSC cooling curves of A) AA6063, B) AA6005A, C) 6082 with low Mg and Si content (6082 low) and D) and 6082 with high $\mathrm{Mg}$ and Si content (6082high). The slowest cooling rate is
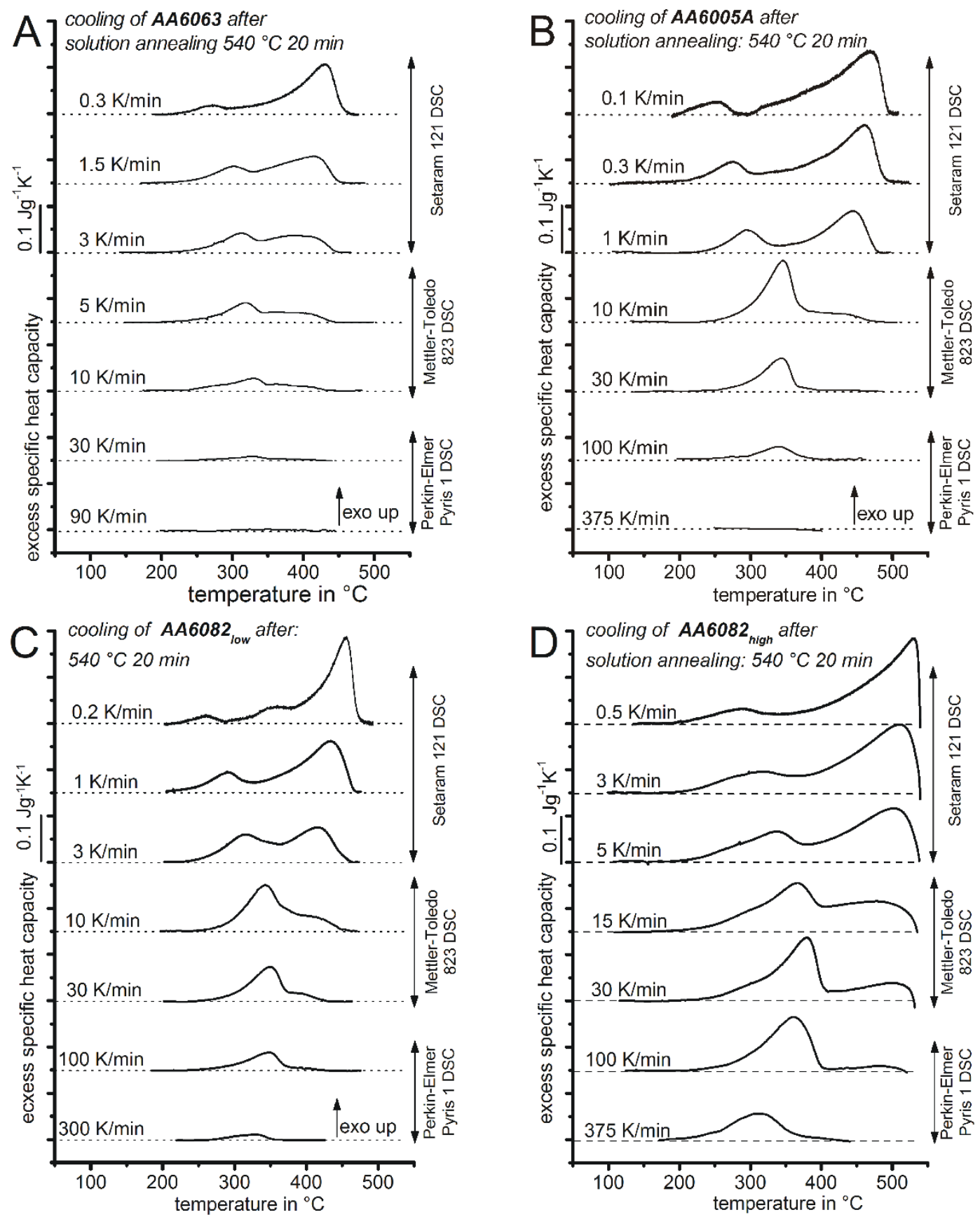

Fig. 3: Selected DSC curves during cooling after solution annealing for A) AA6063, B) AA6005A, C) AA6082 low, AA6082high. 
cooling AA6005A after solution annealing

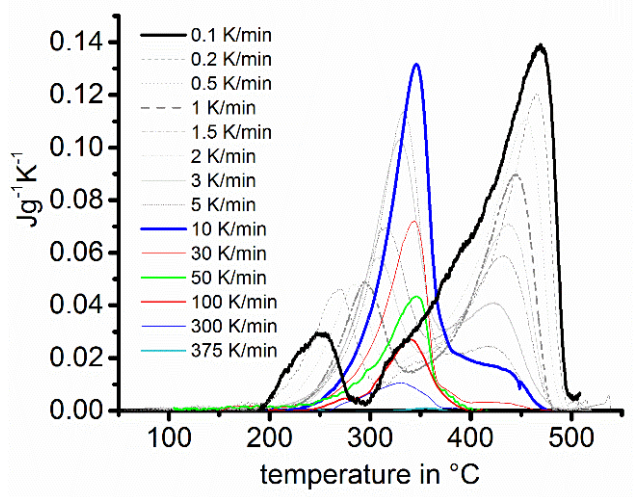

Fig. 4: DSC cooling curves of AA6005A showing the peak developement. plotted on top. For each DSC curve the corresponding zero level is given by a dashed line. As expected, all these DSC cooling curves show only exothermic reactions which are all ascribed to precipitation reactions. In all alloys precipitation during cooling from solution annealing occurs in two main temperature ranges - a high temperature reaction (HTR, typically $\sim 500$ down to $380^{\circ} \mathrm{C}$ ) and a lower temperature reaction $\left(\mathrm{LTR}, \sim 380\right.$ down to $\left.250^{\circ} \mathrm{C}\right)$. These

two main reactions overlap to some degree, and these phases may also compete for the alloying element atoms in solution. From Fig. 3 and in particular from Fig. 4 one can follow the development of both main precipitation reactions areas which correspond to the specific precipitation enthalpy of the reactions. The evolution of the total enthalpy, of the HTR and the LTR is displayed in Fig. 5. The total reactions are increasingly suppressed with increasing cooling rate and at cooling rates above a certain critical rate no exothermic (precipitation) signal can be detected. Cooling then is fast enough to fully suppress all precipitation reactions. The slowest cooling rate at which precipitation is suppressed completely is alloy specific and named upper critical cooling rate (UCCR). This is the optimal cooling rate for the technological cooling process during the age hardening procedure: it ensures optimal mechanical properties whilst minimising quench-induced residual stresses.

Fig. 4 shows that at cooling rates faster than $30^{\circ} \mathrm{K} / \mathrm{min}$, the start of the LTR for AA6005 is about constant at $400 \pm 10{ }^{\circ} \mathrm{C}$ and this reaction peaks for all cooling rates faster than $10{ }^{\circ} \mathrm{K} / \mathrm{min}$ at about 320 $340^{\circ} \mathrm{C}$. For this alloy, at these cooling rates, the composition of the Al-rich phase at the start of the LTR is $\mathrm{Al}-0.61$ at $\% \mathrm{Si}-0.63 a \mathrm{at} \% \mathrm{Mg}$ (see section 4 for the method of evaluation), and according to the solvi determined from first principle modelling in [22] this onset temperature is about $90^{\circ} \mathrm{C}$ below the solvus of the $\beta^{\prime}$ phase. Hence this reaction can not be due to $\beta^{\prime}$ phase formation. Instead, the start temperature corresponds closely (within $10^{\circ} \mathrm{C}$ ) to the solvi of the hexagonal $\mathrm{Al}_{2} \mathrm{MgSi}_{2}$ phase, the hexagonal $\mathrm{Al}_{4} \mathrm{Mg}_{8} \mathrm{Si}_{7}$ phase as well as the orthorhombic Al-Mg-Si phase [22]. It has been shown that the 
Mg:Si ratio in the hexagonal precipitate formed at these temperatures $[27,28]$ is close to 1.15 [27], and hence the dominant reaction is thought to be the formation of this $\mathrm{Al}_{4} \mathrm{Mg}_{8} \mathrm{Si}_{7}$ phase which is termed $\mathrm{B}^{\prime}$.

(For further discussion see Section 6.)
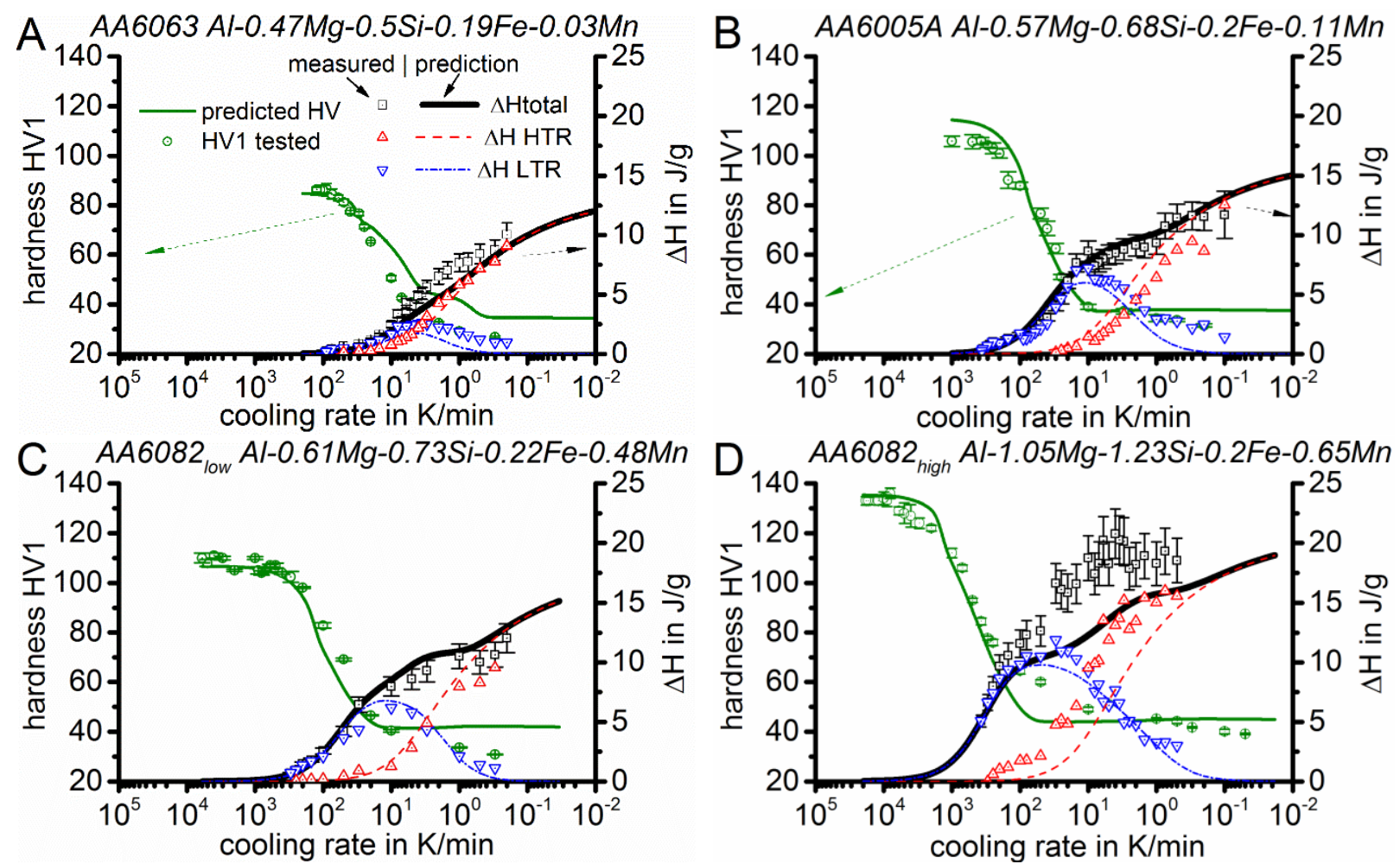

Fig. 5: Comparison of measurement and prediction for specific precipitation enthalpy and hardness after artificial ageing. The specific precipitation enthalpy values are plotted for total reactions (black squares), high-temperature reactions (red triangle tip up) and lowtemperature reactions (blue triangle tip down). (A) AA6063, (B) AA6005A, (C) AA6082 low, (D) AA6082high.

\subsection{Microstructure of quenched samples}

The XRD analysis (samples cooled at $0.05 \mathrm{~K} / \mathrm{min}$ ) showed that the diffraction peaks were due to $\mathrm{Mg}_{2} \mathrm{Si}$ and the Al-rich phase (from [29]). (Spectra not presented.) This observation combined with the analysis in Section 3.1 shows that the precipitation during cooling of our Al-Mg-Si alloys is dominated by two different phases, $\mathrm{Mg}_{2} \mathrm{Si}$ at high temperatures and B' at lower temperatures. The TEM and SEM studies provide further details; they reveal that $\mathrm{Mg}_{2} \mathrm{Si}$ precipitates are square monocrystalline plates inside aluminium grains, the thickness of the $\mathrm{Mg}_{2} \mathrm{Si}$ plates is about one third of their edge length (coarse dark precipitates in Fig. 6). The LTR are dominated by precipitation of the $\mathrm{Mg}_{2} \mathrm{Si}$-precursor phase B'. For a detailed discussion of phase identification see Section 6.2. TEM confirms that B' phase grows as elongated rectanguloids, see Fig. 7-Fig. 9 (see also [28]). Both phases were found in every investigated 


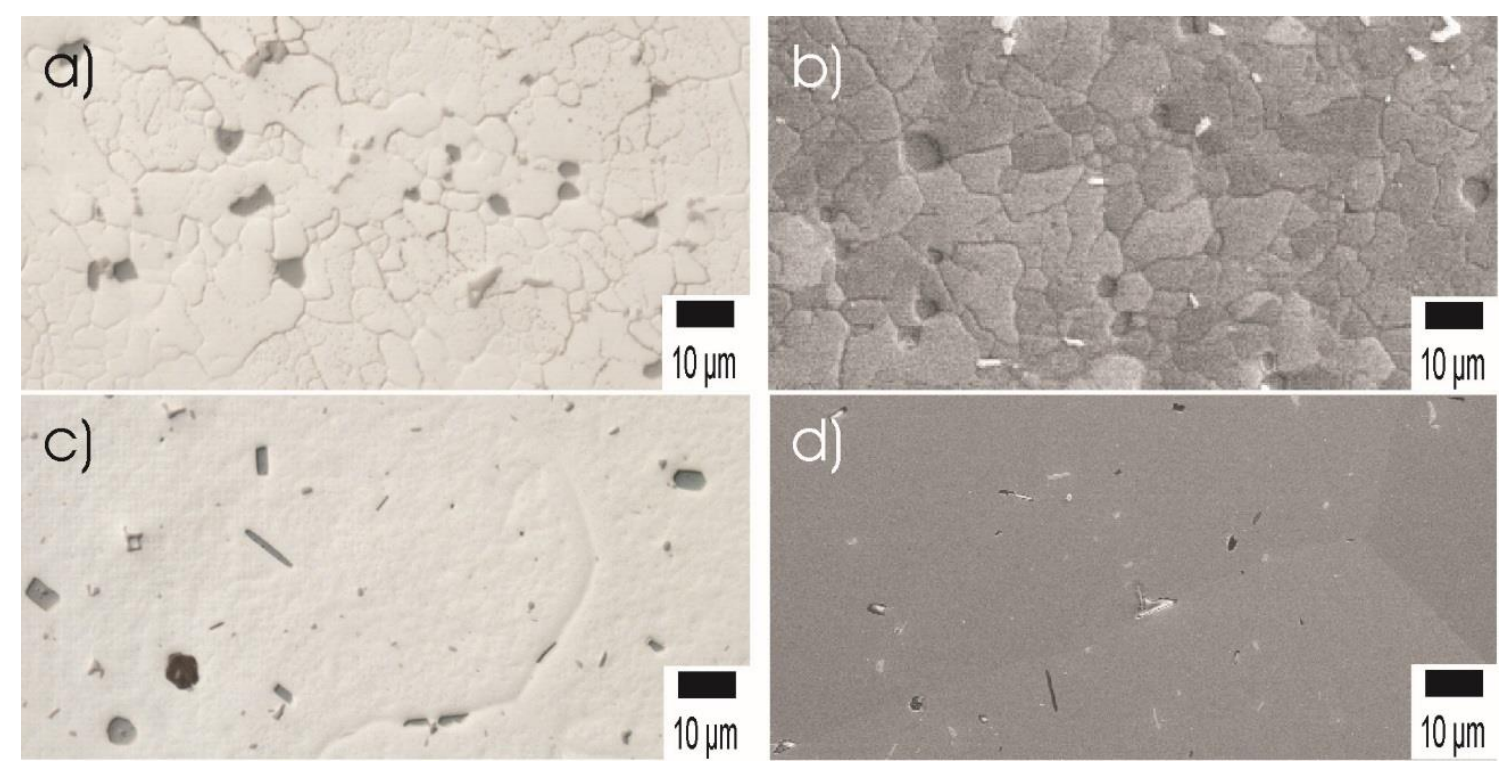

Fig. 6: (a) OM, (b) SEM image of AA6082high after cooling with $0.5 \mathrm{~K} / \mathrm{min}$ - dark $\mathrm{Mg}_{2} \mathrm{Si}$ particles on the grain boundaries possess similar size like grains - no obviously visible intragranular coarse Mg 2 Si precipitates. (c) OM image AA6082low (d) SEM image AA6063, both cooling $0.3 \mathrm{~K} / \mathrm{min}-\mathrm{Mg}_{2} \mathrm{Si}$ on grain boundaries and in particular inside the grains.

sample in which the DSC cooling curves indicate the high- and also the lower temperature reaction occurred.

Selected EM micrographs are displayed in Fig. 7. Fig. 7a) shows a TEM bright field micrograph of AA6005A after slow cooling with $0.1 \mathrm{~K} / \mathrm{min}$. In this cooling condition, the HTR clearly dominate the DSC curve (see Fig. 3 and Fig. 4). Coarse $\mathrm{Mg}_{2}$ Si precipitates with dimensions of up to $\sim 10 \mu \mathrm{m}$ are observed (Fig. 6) and also some smaller $\mathrm{Mg}_{2} \mathrm{Si}$ plates can be observed by TEM, Fig. 7a). Besides the $\mathrm{Mg}_{2} \mathrm{Si}$ plates much finer B' precipitates are present in this cooling condition. B' precipitates formed during cooling are about $100 \mathrm{~nm}$ in thickness and up to several $\mu \mathrm{m}$ in length. A typical microstructure in a cooling condition, in which the LTR possess its highest intensity and dominate the DSC curve, is shown in Fig. 7d) (AA6005A after cooling with $8 \mathrm{~K} / \mathrm{min}$ ). In this sample, relatively small $\mathrm{Mg}_{2} \mathrm{Si}$ plates can be found in TEM, although they are hardly detectable in $\mathrm{OM}$ in this condition. Beside the $\mathrm{Mg}_{2} \mathrm{Si}$ plates, relatively large B' precipitates with diameters of some $100 \mathrm{~nm}$ are detected, see also Fig. $8 \mathrm{a}$ ). The volume fraction of these $B^{\prime}$ precipitates is higher after cooling at $8 \mathrm{~K} / \mathrm{min}$ compared to $0.1 \mathrm{~K} / \mathrm{min}$.

For the setup and selection / setting of some of the parameters in the model, nucleation of the two dominating quench-induced phases are very important issues. The microstructure investigation is therefore particularly focussed on identifying nucleation sites. Fig. 6 displays OM and SEM images of 

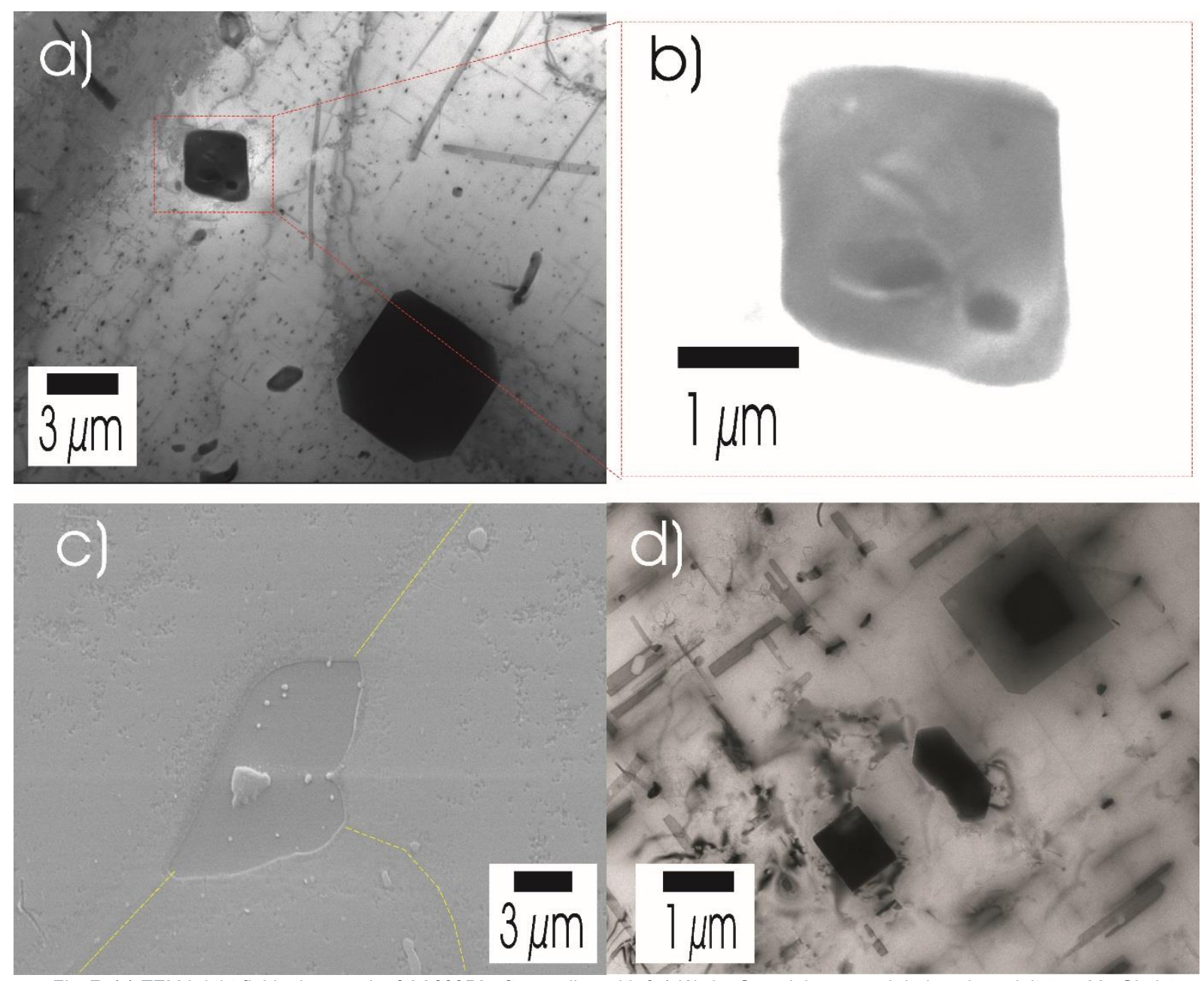

Fig. 7: (a) TEM bright-field micrograph of AA6005A after cooling with $0.1 \mathrm{~K} / \mathrm{min}$. Containing quench induced precipitates: $\mathrm{Mg}_{2} \mathrm{Si}$ plates, Si particle (polygonal shaped precipitate, upper edge), elongated rectanguloid B' precipitates(length about $1 \mu \mathrm{m}$ ) and unidentified large rods (length several $\mu \mathrm{m}$ ). (b) Magnification of $\mathrm{Mg}_{2} \mathrm{Si}$ particle in (a) with high brightness value, showing coarse Al-Fe-Si-Mn-Cr particle as nucleation site inside the $\mathrm{Mg}_{2}$ Si plate. (c) SEM bright field image of same cooling condition like in (a, b) showing a $\mathrm{Mg}_{2}$ Si particle located at a grain boundary. Grain boundaries are highlighted. Even at grain boundaries Mg2 Si nucleation occurs on coarse Al-Fe-Si-Mn particles. (d) TEM bright-field micrograph of AA6005A after cooling with $8 \mathrm{~K} / \mathrm{min}$. Also after cooling with $8 \mathrm{~K} / \mathrm{min}$ the same two main types of quench induced exist. $B^{\prime}$ in significantly coarser particles compared to slower cooling.

AA6082high (A, B), AA6082 low (C), and AA6063 after similar slow cooling conditions, with the grain structures being revealed due to the etching. The grain size of AA6063 and AA6082 low is significantly larger than that of 6082 high.

In all micrographs in Fig. 6 coarse, quench-induced dark $\mathrm{Mg}_{2} \mathrm{Si}$ precipitates with dimensions of up to $10 \mu \mathrm{m}$ are visible. Besides the dark $\mathrm{Mg}_{2} \mathrm{Si}$, the SEM images also show coarse eutectic Al-Fe-Si-Mn precipitates, which possess a bright contrast. Fig. 6 shows $\mathrm{Mg}_{2} \mathrm{Si}$ nucleation occurs in many cases on grain boundaries, and for the alloy with the smallest grain size, AA6082high, it occurs only on grain boundaries. In cases where the grain size is significantly larger than the dimensions of the $\mathrm{Mg}_{2} \mathrm{Si}$ particles, $\mathrm{Mg}_{2} \mathrm{Si}$ is located both inside the grains and on grain boundaries. The quench-induced precipitates in AA6005A are very similar to AA6063 and AA6082 


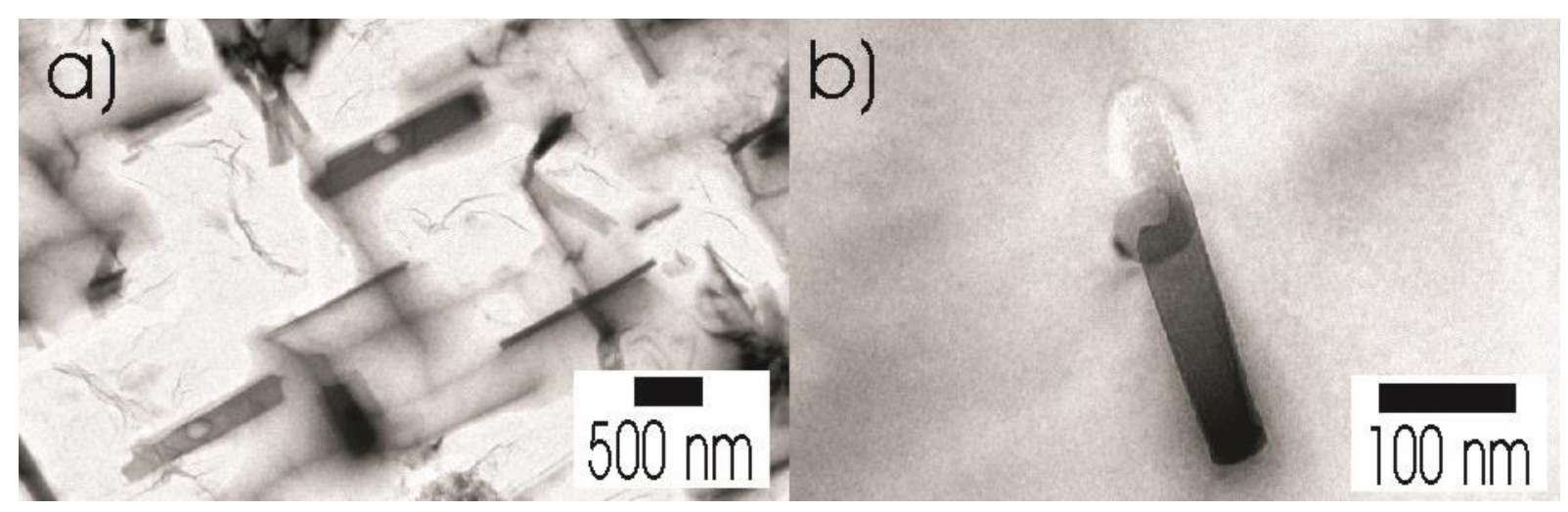

Fig. 8: TEM bright-field micrographs of (a) AA6005A after cooling with $8 \mathrm{~K} / \mathrm{min}$ and (b) AA6063 after cooling with $50 \mathrm{~K} / \mathrm{min}$. In both cases quench induced $B$ ' precipitates are visible, nucleated at dispersoids.

and TEM in Fig. 6. For these alloys, nucleation of $\mathrm{Mg}_{2} \mathrm{Si}$ starts primarily from coarse eutectic Al-Fe-SiMn phases. All $\mathrm{Mg}_{2} \mathrm{Si}$ particles we investigated by SEM / TEM have such coarse Al-Fe-Si-Mn particles inside. This is independent of the $\mathrm{Mg}_{2} \mathrm{Si}$ particle location and was found both for $\mathrm{Mg}_{2} \mathrm{Si}$ particles inside Al grains and on grain boundaries - see Fig. 7 b) and c). We therefore conclude such coarse eutectic Al-Fe-Si-Mn particles to be the dominating and driving nucleation sites for $\mathrm{Mg}_{2} \mathrm{Si}$ formation. Therefore, the amount of nucleation sites for $\mathrm{Mg}_{2} \mathrm{Si}$ is limited.

Fig. 8 and Fig. 9 show that the nucleation of B' occurs on dispersoids. The amount of nucleation sites for B' therefore also is limited. In aluminium technology terminology dispersoids are particles that form during (heating to) homogenisation treatment from the as cast microstructural state. They contain $\mathrm{Mn}, \mathrm{Si}$ and Fe. Those particles formed in solid state are much finer compared to the Al-Fe-Si-Mn phases
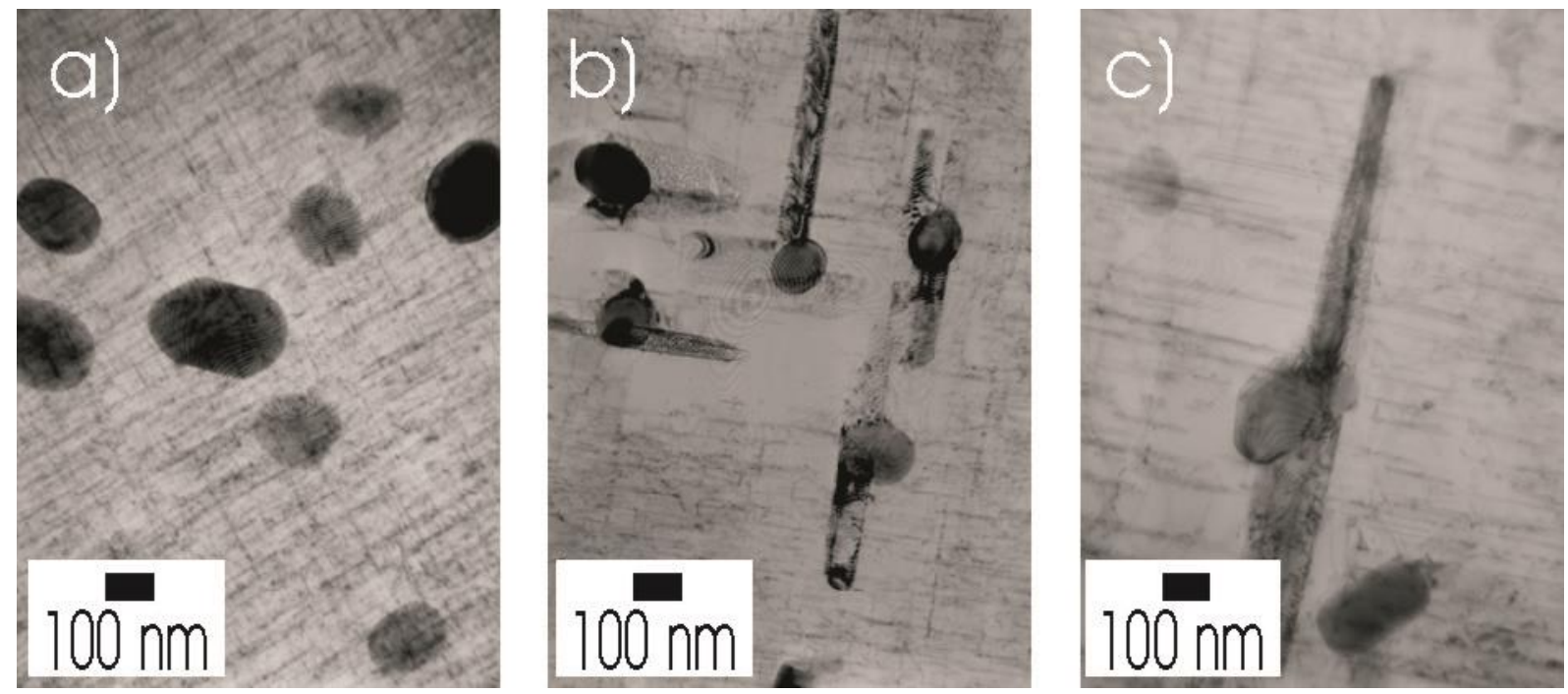

Fig. 9: TEM micrographs of AA6082 typ (Bright Field) of a room-temperature-water quenched (RTWQ) +T6 sample with hardness 97 HV (a), an air cooled (AC) +T6 sample with hardness 88 HV (b) and a slowly air cooled (SAC) +T6 sample with hardness 69.2 HV. In the RTWQ+T6 sample dispersoids are visible as well as a fine dispersion of hardening $\beta^{\prime \prime}$ precipitates, whilst the AC+T6 and SAC+T6 samples in addition shows non-hardening precipitates that apparently nucleated on the dispersoids during the quench. 


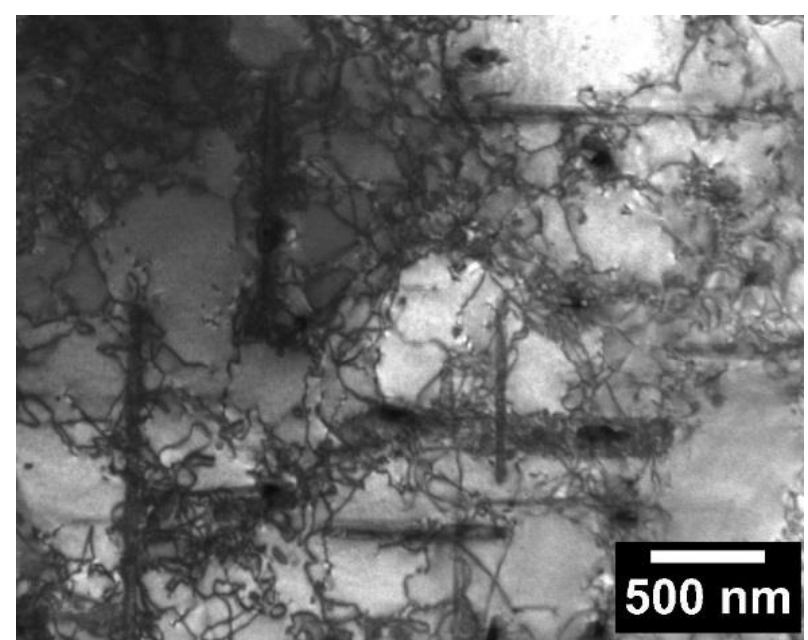

Fig. 10: TEM bright-field image of AA6005A slowly cooled with $0.1 \mathrm{~K} / \mathrm{min}$ showing presence of increased dislocation density around quenched induced B' precipitates. formed in eutectic reactions, which are effective as nucleation sites for $\mathrm{Mg}_{2} \mathrm{Si}$. Similar to those eutectic Al-Fe-Si-Mn particles, the dispersoids are not dissolved during solution annealing and are therefore available as nucleation sites during quenching.

Fig. 9 shows TEM bright field micrographs after three different cooling conditions and additional T6 ageing treatment. After water quenching and ageing (Fig. 9a) two types of particles are visible: globular dispersoids and fine needleshaped hardening $\beta "$ precipitates, which formed during the ageing treatment. After air-cooling and slow air cooling and artificial ageing (Fig. $9 \mathrm{~b}$ and c), additionally $\mathrm{B}^{\prime}$ precipitates with length of several $100 \mathrm{~nm}$ are present. Clearly also in AA6082 typ the quench-induced $\mathrm{B}^{\prime}$ precipitates nucleated on the dispersoids during cooling. Fig. 7-Fig. 9 suggest that in all samples in which $\mathrm{B}^{\prime}$ formation had occurred, all of the dispersoids have a B' precipitate formed on them. Comparison of Fig. $9 \mathrm{a}, \mathrm{b}$ and $\mathrm{c}$ shows that as the cooling rate decreases, the density of the hardening $\beta^{\prime \prime}$ precipitates decreases, and there is evidence of a zone denuded of $\beta^{\prime \prime}$ precipitates around the B' precipitates. Heating DSC experiments showed that the heat content of the $\beta^{\prime \prime}$ formation effect decreased with decreasing cooling rate, confirming the reduced $\beta^{\prime \prime}$ formation. Fig. 10 shows that in many cases a significant amount of dislocations are present around quench-induced precipitates. Therefore, in the strengthening model dislocation strengthening must be taken into account.

The hardness values of the alloys in the aged condition are presented in Fig. 5. 


\section{A model for precipitation during quenching and subsequent age hardening}

\subsection{A model for quench induced precipitation}

In devising a model with general applicability we need to consider that during quenching several types of precipitates can form, including equilibrium phases at high temperatures and metastable phases at lower temperatures. Those reactions occur through a number of mechanisms, incl. precipitation on coarse intermetallics (phases that mostly are formed during solidification), precipitation on grain boundaries and precipitation in the grain, as well as, in particular for the lower temperature phases, precipitation on dispersoids (e. g. $[7,8,25,30])$. These reactions can occur consecutively or in overlapping time intervals. The mechanisms are potentially complicated and can lead to computationally expensive models. We will here derive a new model that is both effective as well as relatively simple, whilst it takes account of the main factors influencing kinetics. On several places in the model derivation we will use simplifications designed to provide a transparent model that can be applied in a computationally efficient manner.

As a starting point of the model, first the atomic fraction of undissolved $\mathrm{Mn}$ and Fe containing phases are calculated using the procedure outlined in [24]. These phases contain Si which will thus be unavailable for further precipitation reactions. The concentrations of elements in the Al-rich phase after solution treatment (i.e. just prior to start of the quench) are denoted as $\mathrm{X}_{\mathrm{Mg}, \mathrm{st}}, \mathrm{X}_{\mathrm{Si}, \mathrm{st}}$.

We consider that multiple reactions occur during the quench producing groups of particles that are distinguished by their structure and/or locations of nucleation (e.g. on grain boundaries or in the grain or on the dispersoid particles). To keep the computational complexity limited and allow a transparent model formulation, we will take the reactions to be consecutive, e.g. the interaction between the reactions occurs through taking the final state achieved after preceding reaction(s) to be the starting state of the next reaction. In the model formulation below we will present the equations for 2 reactions, but in principle the scheme can be repeated to include more consecutive reactions. As shown in Section 
3 , precipitation in $6 x x x$ alloys is mainly dominated by two reactions $-\beta\left(\mathrm{Mg}_{2} \mathrm{Si}\right)$ phase, followed by the formation of $\mathrm{B}^{\prime}\left(\mathrm{Mg}_{5} \mathrm{Si}_{4} \mathrm{Al}_{2}\right)$. Therefore these two reactions are incorporated in the model.

The total atomic fraction of quench induced precipitates, $y_{Q}$, that forms is taken using an expansion of the quench factor model [2] which incorporates the Starink-Zahra model [31]:

$$
y_{Q I P}=y_{\text {QIP }}(\max )\left(1-\left[\frac{(k Q)^{n}}{\eta_{i}}+1\right]^{\eta_{i}}\right)
$$

where $Q$ is the quench factor [2], $n$ is the reaction exponent, $k$ is a rate constant, $\eta_{i}$ is the impingement factor and $y_{\mathrm{QIP}}(\max )$ is the maximum amount that can form on very slow cooling rate, which is defined by the concentrations of dissolved $\mathrm{Mg}$ and $\mathrm{Si}$ in the Al-rich phase prior to cooling (/quenching). For multiple reactions there are multiple groups i.e. there is a $y_{\mathrm{QIP}, 1}, y_{\mathrm{QIP}, 2}$, etc, each with a distinct set of parameters $k, n, \eta_{\mathrm{i}}$, etc.

Following [2], $Q$ is defined as:

$$
Q=\int_{t=0}^{t} \frac{d t}{C_{t}}
$$

For constant cooling rates $Q$ is proportional to the time during the quench, which in turn is proportional to $1 / \beta$. We can thus combine the latter two equations to:

$$
y_{Q I P}=y_{Q I P}(\max )\left(1-\left[\frac{\left(k_{2} / \beta\right)^{n}}{\eta_{i}}+1\right]^{\eta_{i}}\right)
$$

In the latter equation the rate constant $k_{2}$ depends on a number of factors that drive the transformation rate, including density of nuclei, and diffusion rate.

A key part of the model is a functional description of the amount of precipitate phases that form during the cooling as a function of the main parameters (composition and cooling rate). We will here not attempt to provide a full ternary solution but instead determine the main factors that cause variations in $k_{2}$ and $n$ in Eq. 3. To achieve this, we use the concept from the extended volume approach that for small $y_{\mathrm{QIP}} / y_{\mathrm{QIP}}(\max )$ the latter equation can be approximated as (see e.g. [32,23]):

$$
y_{Q I P}=y_{Q I P}(\max )\left(k_{2} / \beta\right)^{n} \propto y_{Q I P}(\max )\left(k_{2} t_{c}\right)^{n}
$$


where $t_{\mathrm{c}}$ is the cooling time. This can be compared to the growth rate of spherical precipitates in a binary alloy, which is given by (see e.g. [33]):

$$
\frac{d R}{d t}=\frac{\bar{c}(t)-c_{m}}{c_{p}-c_{m}} \frac{D}{R_{p}}
$$

where $D$ is the diffusivity, $R_{p}$ is the radius of the precipitate, $C_{m}$ is the concentration of the parent phase at the interphase of the nucleus, $c_{p}$ is the concentration of alloying elements in the particle, $\bar{c}(t)$ is the average concentration of alloying elements in the parent phase. For the initial growth stage, $\left(\bar{c}(t)-c_{m}\right)$ can be considered to be constant, and the latter equation integrates to:

$$
R_{p}^{2}=A \frac{\bar{c}(t)-c_{m}}{c_{p}-c_{m}} D t
$$

From the latter equation we can see that the volume of a precipitate is proportional to $t^{3 / 2}$ and a number of factors as shown by:

$$
V \propto R_{p}^{3}=\left(\frac{\bar{c}(t)-c_{m}}{c_{p}-c_{m}} D t\right)^{3 / 2}
$$

As the temperature for the reactions will depend on composition (see e.g. Fig. 2), the magnitude of $D$ during the reaction will be strongly alloy dependent. We can derive the composition dependency by using the following approach in which we combine the Arrhenius expression for the temperature dependency of diffusivity and the regular solution expression for the solvus to arrive at an equation providing the composition dependency of the reaction rate. Thus we firstly apply:

$$
D=D_{o} \exp \left(-\frac{E_{D}}{R T}\right)
$$

where $E_{\mathrm{D}}$ is the activation energy for diffusion of the atomic species that is rate determining, $D_{0}$ is the diffusion preexponential factor. Secondly, we consider that formation of the quench-induced precipitates starts when the temperature reaches the solvus of the quench-induced precipitates. We apply a regular solution model expressions (see e.g, [34-37]), which provides:

$$
c_{M g}{ }^{q} c_{S i}=C \exp \left[\frac{-\Delta H_{M g 2 S i}}{R T}\right]
$$


where $c_{\mathrm{Mg}}$ and $c_{\mathrm{Si}}$ are the solubilities of $\mathrm{Mg}$ and $\mathrm{Si}$ as given by the solvus, $q$ is the $\mathrm{Mg}: \mathrm{Si}$ ratio in the phase, i.e. the phase is $\mathrm{Mg}_{q} S i A I_{r}, C$ is a constant and $\Delta H_{M g q S i}$ is the enthalpy change due to the formation of the $\mathrm{Mg}_{q} \mathrm{SiAl}$ r phase. (The high temperature reaction is due to $\mathrm{Mg}_{2} \mathrm{Si}$ i.e. $q=2$ and $r=0$.) The latter two equations can be combined to provide a relation between $D$ and the alloy composition:

$$
\frac{D}{D_{o}}=\left(\frac{c_{M g}{ }^{q} c_{S i}}{C}\right)^{\frac{E_{D}}{\Delta H_{M g g S i}}}
$$

We can now combine Eqs 4,7 and 10 to provide the functional relation between $k_{2}$ and the composition for the case that the number of growing precipitates is independent of the $\mathrm{Mg}$ and $\mathrm{Si}$ content of the alloy (this is the case for a limited number of nuclei):

$$
k_{2}^{H T R}=k_{o}\left(\frac{c_{M g}{ }^{q} c_{S i}}{C}\right)^{\frac{E_{D}}{\Delta H_{M_{g} q S i}}}\left[y_{Q I P}(\max )\right]^{p}
$$

in which $p$ equals $1 / 3$. The latter equation is applied for the HTR.

A further factor that influences $k_{2}$ is the density of nuclei that grow. From the investigation performed (Section 3) it is clear that for the LTR the density of nuclei is determined by the density of dispersoids. As the composition of the dispersoids are $\beta-\mathrm{Al}_{5} \mathrm{FeSi}$ and $\alpha-\mathrm{Al}_{15}(\mathrm{FeMn})_{3} \mathrm{Si}$ [38-40], the $\mathrm{Fe}$ and $\mathrm{Mn}$ content of the alloys will influence the volume fraction of dispersoid phases. Formation of the various phases during solidification of $6 x x x$ type alloys involves at least 5 phases including $3 \mathrm{Mn}$ and/or $\mathrm{Fe}$ bearing ones; the solidification is complex and although many details are known $[40,38]$ it is at present not fully understood. We propose to use the following simplified treatment for the $k_{2}$ for the LTR:

$$
k_{2}^{L T R}=k_{o}\left(x_{M n}^{g}+x_{F e}^{g}\right)\left(\frac{c_{M g}{ }^{q} c_{S i}}{C}\right)^{\frac{E_{D}}{\Delta H_{M g} g i}}\left[y_{Q I P}(\max )\right]^{p}
$$

A justification for the $\left(\mathrm{x}_{\mathrm{Mn}}+\mathrm{x}_{\mathrm{Fe}}\right)$ term in the latter equation is as follows. We will consider that according to a Scheil type model of solidification in a binary eutectic system with hypoeutectic composition the amount of dispersoid-forming alloying elements dissolved in the Al-rich phase during solidification of a binary alloy increases approximately proportional to the gross alloying content of the alloy. Thus in such a simple system the volume fraction of dispersoids that form during homogenisation 
treatment is approximately proportional to the alloying content. We make the assumption that this proportionality holds in good approximation for the complex 6xxx alloys and that the sum of gross Fe and Mn determine the relevant alloying content. Then, assuming that the alloying content does not influence the size of the dispersoids, the density of dispersoids is proportional to $\left(\mathrm{x}_{\mathrm{Mn}}+\mathrm{x}_{\mathrm{Fe}}\right)$.

Thus after determining 3 parameters $\left(k_{0}, y_{\text {QIP }}(\max )\right.$ and $\left.\eta_{i}\right)$, the above treatment allows determination of $y_{\mathrm{QIP}, 1}$ for a set of Al-Mg-Si based alloys. With $y_{\mathrm{QIP}, 1}$ determined, the composition of the Al-rich phase can be determined from a mass balance and $\mathrm{x}_{\mathrm{Mg}, \mathrm{st}}, \mathrm{X}_{\mathrm{Si} \text { ist. }}$. The composition of the matrix after reaction 1 will be denoted as $\mathrm{x}_{\mathrm{Mg}, \mathrm{q} 1}, \mathrm{x}_{\mathrm{Si}, \mathrm{q} 1}$. The amount of precipitates forming during reaction 2 , $y_{Q I P, 2}$ can be determined based on the state reached after the preceding reaction. The composition of

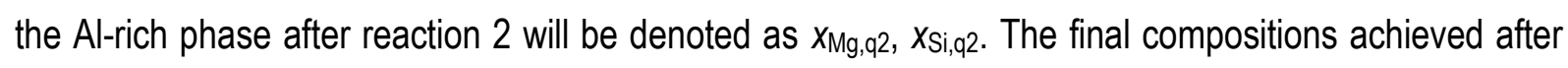
completion of cooling/quenching will be denoted by $\mathrm{x}_{\mathrm{Mg}, \mathrm{q}}, \mathrm{X}_{\mathrm{Si}, \mathrm{q}}$.

\subsection{A model for strength/hardness of alloys T6 aged after cooling}

We will use the general approximation of the superposition of strengthening mechanisms described in [41]

$$
\sigma_{y}=\sigma_{g b}+M\left(\tau_{o}+\tau_{s o l}+\tau_{d}+\tau_{c l}+\tau_{p r}\right)
$$

where $\sigma_{\mathrm{gb}}$ is the yield strength contribution due to grain boundaries, $\tau_{\mathrm{d}}$ is the critical resolved shear stress (CRSS) increment due to stored dislocations (introduced by plastic deformation), $\tau_{\text {sol }}$ is the CRSS increment due to dissolved alloying atoms, $\tau_{\mathrm{pr}}$ is the CRSS increment due to precipitates, $\tau_{\mathrm{cl}}$ is the CRSS increment due to shearable clusters, $\tau_{0}$ is the friction resolved shear stress and $M$ is the Taylor factor.

On artificial ageing $\beta "$ precipitates form [42], and we will consider that in the T6 condition the remaining $\mathrm{Mg}$ and $\mathrm{Si}$ in solution given by the metastable solvus of the precipitates. This metastable solvus is taken from first principles modelling of the monoclinic $\beta^{\prime \prime}\left(\mathrm{Mg}_{5} \mathrm{Si}_{4} \mathrm{Al}_{2}\right)$ in $[43,22]$, which according to the first principle models is the most stable form of a range of potential closely related monoclinic $\beta$ " structures (which include the $\mathrm{Mg}_{5} \mathrm{Si}_{6}$ ) [43]. From [22] we take the solvus of the monoclinic $\beta^{\prime \prime}\left(\mathrm{Mg}_{5} \mathrm{Si}_{4} \mathrm{Al}_{2}\right)$ phase precipitate in the absence of interface energy effects, and from [43] we take the 
result that the interfacial energy terms reduce the enthalpy change by about $8 \%$. The latter result was obtained for precipitates with cross section of $6 \times 5 \mathrm{~nm}^{2}$, which corresponds well with $\beta$ " precipitates seen in our TEM experiments (Fig. 9). (The result is that the solubilities for a balanced Al-Mg-Si at ageing temperatures is about doubled due to the interfacial energy.)

The concentration of the main alloying elements in the Al-rich phase after the artificial ageing treatment are denoted as $\mathrm{X}_{\mathrm{Mg}, \mathrm{T} 6}$ and $\mathrm{X}_{\mathrm{Si}, \mathrm{T} 6}$. The total amount of $\mathrm{Si}$ and $\mathrm{Mg}$ in the hardening precipitates, $y_{\mathrm{hpr}}$, is then given by:

$$
y_{h p r}=x_{M g, q}-x_{M g, T 6}+x_{S i g, q}-x_{S i, T 6}
$$

In the literature a number of strengthening models are available which provide the relation between $\tau_{\mathrm{pr}}$ and the volume fraction of precipitates, their sizes or average size and other parameters (see e.g. [42]. In the appendix, it is shown that the yield strength of Al-Mg-Si based alloys increases linearly with the amount of $\mathrm{Mg}$ and $\mathrm{Si}$ in the hardening precipitates and hence we take:

$$
\Delta \tau_{p r, a g}=K_{\beta^{\prime \prime}} y_{h p r}
$$

where $K_{\beta^{\prime \prime}}$ is a proportionality constant which is related to the energy required to move a dislocation through the coherent $\beta^{\prime \prime}\left(\mathrm{Mg}_{5} \mathrm{Si}_{4} \mathrm{Al}_{2}\right)$ phase precipitate. Hence, we are here applying a treatment for shearable precipitates. The linear relation between strength and amount of alloying atoms in the metastable precipitates is similar to strengthening due to co-clusters in which strengthening is dominated by the bonds between the two atoms in the cluster [24] (in this case Si and Mg). Consistent with the present treatment, Midling and Grong [44] also applied a linear relation between strengthening and volume fraction of precipitates.

The $\mathrm{B}^{\prime}$ precipitate particles precipitated during the quench will also contribute some limited strengthening, and this is treated using classical Orowan strengthening [45]. This contribution is termed $\tau_{\mathrm{pr}, \mathrm{qip}}$. The superposition of the total strengthening due to these 2 types of obstacles will be taken according to a quadratic superposition [46-48]: 


$$
\Delta \tau_{p r}{ }^{2}=\Delta \tau_{p r, a g}{ }^{2}+\Delta \tau_{p r, q i p}{ }^{2}
$$

Using the Hall-Petch relation with a Hall-Petch constant taken from [49], one can determine that for typical $6 \mathrm{xxx}$ alloys $\sigma_{\mathrm{gb}}$ is only about $4 \mathrm{MPa}$. As the alloys contain up to about 3 vol\% intermetallic particles, some dislocations can be generated due to the misfit caused by differences in the thermal expansion coefficients (see e.g. Fig. 10). To address this, we add a prediction of dislocation density generated by this to the model, following the work by Chawla [50]. In applying this dislocation generation model, we take the typical temperature range over which dislocations are accumulated, $\Delta T$, and the typical difference in coefficient of thermal expansion between matrix and precipitates, $\Delta \alpha$, from an earlier analysis in [24]. The contribution to the strength is small, up to $6 \mathrm{MPa}$ for $6 \mathrm{xxx}$ alloys with the higher $\mathrm{Mn}$ and Fe contents (high Mn and Fe 6xxx alloys typically contain over 0.1 at\% of each element). In addition, we also add strengthening due to stress transfer to the intermetallic particles by applying the treatment in $[51,52]$. This contribution is also low, with typically about $1 \%$ increase in yield strength for alloys with the higher $\mathrm{Mn}+\mathrm{Fe}$ content.

We will test the model to an extensive set of data comprising both proof strength and hardness data of a range of Al-Mg-Si alloys. We will provide predictions of Vickers hardness based on modelled yield strength through a conversion which is calibrated by pairs of proof strength - hardness data from databases on commercial alloys. The presence of substantial amounts of non-shearable dispersoid particles in the commercial alloys will affect the hardness through their influence on strain hardening [53,46,54], and hence we will adopt a two-term conversion, which is given by:

$$
H V=C_{\sigma-H V}\left(\sigma_{0.2}+0.25 G \sqrt{\frac{b f_{n s}}{2 r_{n s}}} \sqrt{\varepsilon_{e f f}}\right)
$$

where $f_{\text {ns }}$ is the volume fraction of non shearable particles, $G$ is the shear modulus, $r_{n s}$ is the average radius of non shearable particles, $C_{\sigma-H v}$ is the conversion parameter (see below) and $\varepsilon_{e f f}$ is the effective strain reached in indentation hardness, here taken as 0.08 . The second term is the strain hardening term as given in $[53,46,54]$, which amounts to about $10 \%$ of the hardness for our commercial $6 x x x$ 
alloys. $f_{\mathrm{ns}}$ is taken from model predictions, $r_{\mathrm{ns}}$ is taken from TEM data, and $C_{\mathrm{s}-\mathrm{HV}}$ is determined from pairs of proof strength - hardness data on commercial 6xxx alloys from databases $[55,56]$.

Table 2: Parameters in the model.

\begin{tabular}{ll}
\hline Parameter Value $\quad$ Notes / Source \\
\hline General parameters \\
$b \quad 2.84 \times 10^{-10} \mathrm{~m}$
\end{tabular}

Reaction 1: $\beta$ formation

$\begin{array}{lll}\eta_{\mathrm{i}} & 0.4 & \begin{array}{l}\text { From fit to data } \\ k_{0}\end{array} \\ n & 1.5 \times 10^{9} & \begin{array}{l}\text { From fit to data } \\ \text { According to model for diffusion controlled reactions [23] } \\ \text { Activation energy for diffusion of Mg in Al, the main component of } \\ \text { the phases; average of two works [57,58] }\end{array} \\ E_{\mathrm{D}} & 131 \mathrm{~kJ} / \mathrm{mol} & \begin{array}{l}\text { From solvus data in [59] } \\ \Delta H_{\mathrm{Mg} 2 \mathrm{Si}}\end{array} \\ \rho_{\beta} & 140 \mathrm{~kJ} / \mathrm{mol} & {[60]}\end{array}$

Parameter Value Notes / Source

Reaction 2: B' formation

$\begin{array}{lll}\eta_{\mathrm{i}} & 2 & \begin{array}{l}\text { distributed precipitates } \\ k_{0}\end{array} \\ n & 1.4 \times 10^{14} & \begin{array}{l}\text { From fit to data } \\ \text { According to model for diffusion controlled reactions [23] }\end{array} \\ E_{\mathrm{D}} & 11 / 2 & \begin{array}{l}\text { Activation energy for diffusion of Mg in Al, the main component of } \\ \text { the phases; average of two works }[57,58]\end{array}\end{array}$

Strength model

\begin{tabular}{|c|c|c|}
\hline $\begin{array}{l}\tau_{0} \\
M \text { (for tensile tests }\end{array}$ & $6 \mathrm{MPa}$ & [24] \\
\hline in L direction) & 2.73 & $\begin{array}{l}\text { For tensile tests in the longitudinal direction, see [24] } \\
\text { For all other tensile and hardness tests; obtained from self- }\end{array}$ \\
\hline$M_{\text {(all other tests) }}$ & 2.6 & $\begin{array}{l}\text { consistent models [61], see also [62] } \\
\text { Determined from literature data on strength of } 6 x x x \text { alloys }- \text { see }\end{array}$ \\
\hline$K_{\text {hpr }}$ & $\begin{array}{l}15.5 \mathrm{GPa} \\
27 \mathrm{GPa}\end{array}$ & appendix \\
\hline$k_{\mathrm{Si}}$ & $800 \mathrm{MPa}$ & From [24] \\
\hline$k_{M g}$ & $590 \mathrm{MPa}$ & From $[47,63,64]$ \\
\hline$\Delta \alpha$ & $1.710^{-5}$ & $\begin{array}{l}\text { Estimated from data in [65], see also [24] } \\
\text { Typical temperature interval over which misfit dislocations are }\end{array}$ \\
\hline$\Delta T$ & $400 \mathrm{~K}$ & generated. \\
\hline
\end{tabular}




\section{Model parameters and predictions}

To apply the model, first all the model parameters need to be determined. There are 4 types of model parameters: i) parameters that are well known and well established (e.g. $G, b)$, ii) parameters that are known to a good accuracy from a range of investigations (e.g. $E_{\mathrm{D}}, \mathrm{kmg}_{\mathrm{mg}} \mathrm{ksi}_{\mathrm{i}}$ ), or from models (e.g. $\eta_{\mathrm{i}}$ for the low temperature reaction), iii) parameters that can be determined from an analysis of literature and handbook data (e.g. $\Delta H_{\mathrm{pr}}, \tau_{0}$ ) and iv) parameters that are unknown and need to be determined through fitting. We have measured a total of over 1000 data points (hardness, enthalpy changes and $\beta$ volume fractions for a wide range of cooling rates) and hence there are a multitude of ways in which we can attempt to determine the values of the fittable (type iv) parameters, of which there are 4 ( $\eta_{i}$ for the high temperature reaction, $k_{0}$ for both of the reactions, plus $\left.\Delta H_{B}\right)$. We will here use a set of fittable parameters that provide a good balance for the range over which the model is considered to be valid. All model parameters are presented in Table 2.

A comparison of model predictions with measured hardness data is presented in comparisons with the $\Delta H$ values in Fig. 5. Generally an excellent correspondence is observed.

The main area where deviations occur is for $\Delta H$ at slow cooling rates for the AA6082high alloy. It is thought that this is due to the higher density of nucleation sites for $\beta$ precipitates due to the substantially
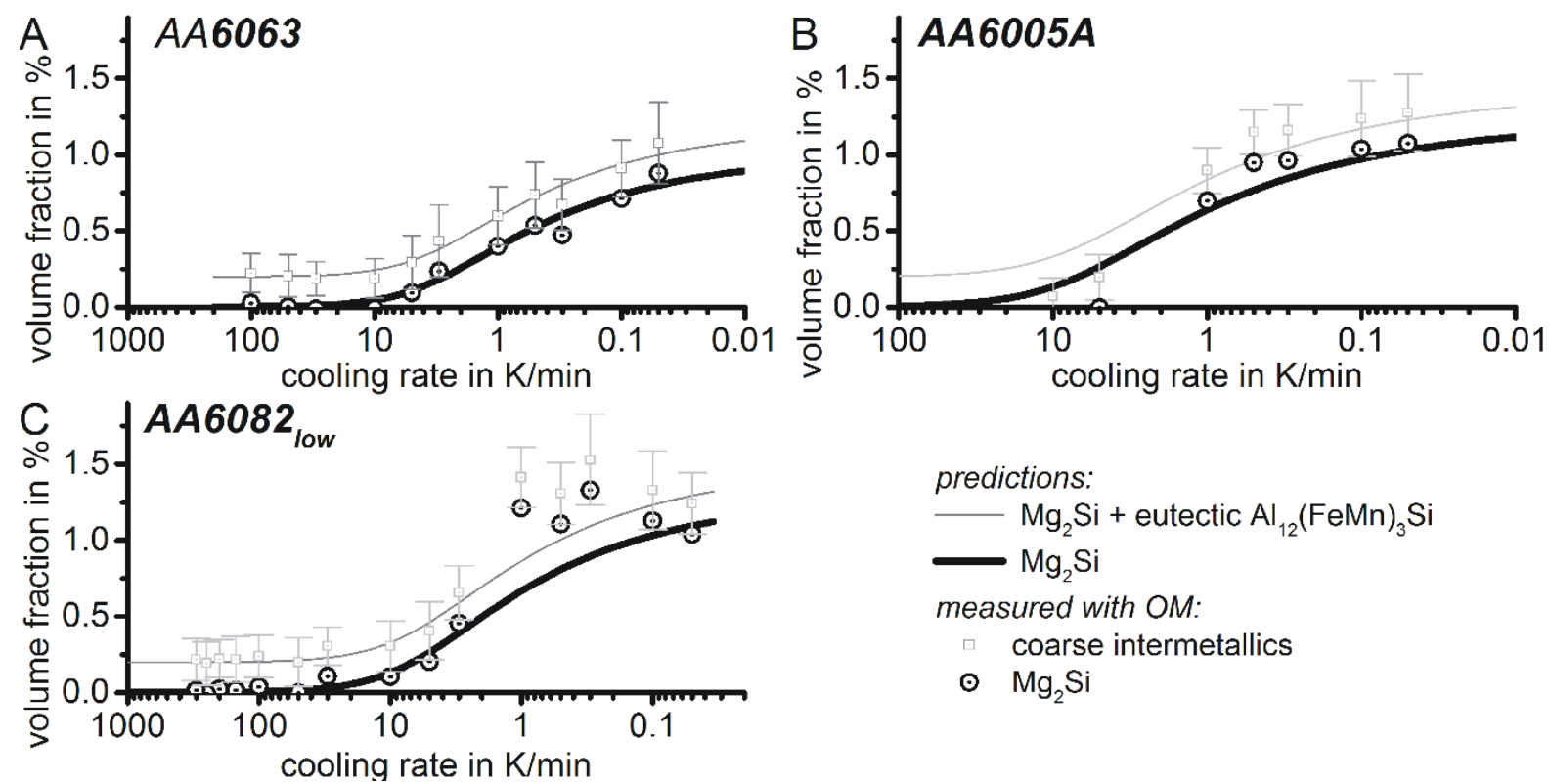

$$
\begin{aligned}
& \text { predictions: } \\
& -\mathrm{Mg}_{2} \mathrm{Si}+\text { eutectic } \mathrm{Al}_{12}(\mathrm{FeMn})_{3} \mathrm{Si} \\
& \mathrm{Mg}_{2} \mathrm{Si} \\
& \text { measured with } \mathrm{OM} \text { : } \\
& \square \quad \text { coarse intermetallics } \\
& \odot \mathrm{Mg}_{2} \mathrm{Si}
\end{aligned}
$$

Fig. 11: Measured and predicted volume fractions. 
reduced grain size and increased amount of eutectic phases for this alloy as compared to the other alloys. Nevertheless, the predictive capability of the model with regards to the quench sensitivity at the commercially important rates is not impaired, and the hardness is correctly predicted for all cooling rates down to about $1 \mathrm{~K} / \mathrm{min}$.

It is worthwhile to briefly consider some of the main parameters and their values. For the LTR, the precipitates are homogeneously distributed and we can take $\eta_{i}$ from the assessment in [23]. For the HTR the precipitates are distributed very inhomogeneously and no model assessment to determine $\eta_{\mathrm{i}}$ is available. The value of $\Delta H_{\mathrm{Mg} 2 \mathrm{Si}}$ is determined from solubility data in [59] whilst $\Delta H_{\mathrm{B}^{\prime}}$, for which no data is available in the literature, is fitted. The magnitude of modelled $\Delta H$ in Fig. 5 depends strongly on these 2 values, with $\Delta H_{\mathrm{B}^{\prime}}$ determining for a large extend the $\Delta H$ where an intermediate plateau is visible, such as in AA6005 between about 1 and $10 \mathrm{~K} / \mathrm{min}$. The general good model predictions for these plateau values of $\Delta H$, as well as for the maximum values of $\Delta H$ for the alloys in which precipitation is fastest, provides good proof that both $\Delta H_{\mathrm{Mg} 2 \mathrm{Si}}$ and $\Delta H_{\mathrm{B}}$, used here are accurate. Accuracy of the values is estimated to be about $\pm 10 \%$.

Fig. 11 presents a comparison of measured and predicted volume fractions of $\beta-\mathrm{Mg}_{2} \mathrm{Si}$ for AA6063, AA6005A and AA6082 low. The volume fraction is predicted for $\mathrm{Mg}_{2} \mathrm{Si}$ and a sum of $\mathrm{Mg}_{2} \mathrm{Si}$ and eutectic $\mathrm{Al}_{12}(\mathrm{FeMn})_{3} \mathrm{Si}$ as it was measured by OM (see section 2.3 for details). The measured data is predicted well.

\section{Discussion}

\subsection{Model efficiency and model accuracy}

The present model includes integrated predictions of volume fractions of quench-induced phases and strength, through a formulation which allows evaluation with minimal computation time: all equations are closed-form and no iterations or differential time evolution computations are required. The results are very good: enthalpy changes during cooling are generally predicted well, hardness is predicted to an accuracy of about $5 \mathrm{HV}$ for cooling rates faster than $2 \mathrm{~K} / \mathrm{min}$ and volume fractions of 
$\beta-\mathrm{Mg}_{2} \mathrm{Si}$ precipitates are also predicted well. The shape of the $\Delta H$ vs cooling rate curves are predicted very well, both for the LTR and the HTR as well as the sum of the two. Small shifts along the cooling rate axis are observed for some alloys, which are thought to be mainly due to small changes in the number of nucleation sites between the various alloys caused by factors beyond the capability of the present model. In particular, for the $\mathrm{B}^{\prime}$ formation reaction, the density of dispersoids will determine the number of nuclei. To improve the model in this respect one would need to further refine prediction of the density of the dispersoids.

The model is further consistent with all qualitative data obtained from the present microstructural investigation as well as investigations in other work (e.g. $[7,2,66-68])$. Whilst the success of the model is clear, it is valuable to discuss the consequences of the approximations that are introduced, and the limitations of the model.

\subsection{Phases formed during quenching/cooling}

The model contains 2 reactions which are taken as formation of $\beta-\mathrm{Mg}_{2} \mathrm{Si}$ phase, followed by the formation of $\mathrm{B}^{\prime}\left(\mathrm{Mg}_{5} \mathrm{Si}_{4} \mathrm{Al}_{2}\right)$ phase. The experimental evidence in section 3 (XRD and SEM) supports the formation of $\beta-\mathrm{Mg}_{2} \mathrm{Si}$ on cooling and also other investigations have revealed the formation of this phase at temperatures above $400{ }^{\circ} \mathrm{C}[7,25,66-68]$. The lower temperature reaction is caused by the formation of semi-coherent precipitates on the dispersoids. Zajac et al. suggested that " $\mathrm{Mg}_{2} \mathrm{Si}$ precipitates as $\beta$ 'phase" [66]. During the TEM-SAED investigation in [7] we obtained SAED patterns showing a hexagonal, semi-coherent structure of these precipitates. In the literature a range of suggestions have been provided for similar SAED patterns and both $\beta^{\prime}$ and $B^{\prime}$ phases are consistent with the observed SAED patterns $[7,27,69-72]$. Compared to these previous studies we have in this work provided a new assessment that can distinguish between these 2 phases: we have compared the start temperatures measured by highly accurate fast cooling DSC with the very recently published solvi for the $\beta^{\prime}$ and $\mathrm{B}^{\prime}$ phases obtained from thermodynamic modelling incorporating first-principles calculations [22]. This 
comparison indicates that start of the reaction for heating rates $>30 \mathrm{~K} / \mathrm{min}$ is inconsistent with the solvus of $\beta^{\prime}$ and instead is consistent with $B^{\prime}$ phase formation. This finding is incorporated in the model.

The Si phase is thermodynamically stable in the present alloys (see [39]), and might be considered as a possible $3^{\text {rd }}$ phase forming during cooling. It seems possible that a minor amount of Si phase can form in alloys with excess Si under certain conditions that have little commercial relevance such as very slow cooling (typically $<1 \mathrm{~K} / \mathrm{min}$ ). In such a case the excess $\mathrm{Si}$ in solution would be expected to precipitate as a Si rich phase. Indeed the TEM work (Fig. 7) has shown that at extremely low cooling rates $(0.1 \mathrm{~K} / \mathrm{min}$ ) a small fraction (less than $\sim 5 \%$ ) of the precipitate phase is Si phase. (The XRD does not detect these small amounts of Si phase, and only the $\beta$ and Al-rich phase are detected.) In line with this assessment, we can see that for selected cooling rates there is evidence in the DSC curves that more than two reactions are involved. This is seen in Fig. 3C) 6082 low during cooling with the extremely slow rate of $0.2 \mathrm{~K} / \mathrm{min}$. Such minor deviations from model predictions for small sections of the alloy-heat treatment space are inherent to the complexity of the multi-component, multiphase alloys treated at cooling rates over about 6 decades; and the present model is thought to provide an excellent balance of high accuracy and low computational costs, achieved through a judicious choice of modelling approaches.

\subsection{Model parameters: nucleation, impingement, enthalpies of formation}

The model parameters used in the model can be compared with a range of data to further elucidate the reactions and the thermodynamics. We will here consider the most relevant parameters.

An analysis of diffusion-controlled precipitation reactions in conjunction with a new model for diffusion controlled reactions $[23,73]$ has shown that the reaction parameter $n$ is generally $1 \frac{1}{2}$, and only in cases where nucleation is continuous during the entire reaction the higher value of $2 \frac{1}{2} 2$ is possible. In the present system it is clear from the microstructure data that nucleation is heterogeneous, occurring on defects and particles. Thus the reaction parameter $n$ was taken as $1 \frac{1}{2}$, and the excellent correspondence of the shape of the $\Delta H$ vs heating rate data to model predictions provides further proof that this part of the model and the theory on which it is based are sound. 
We consider the state of the art of modelling of heterogeneous nucleation to be too limited to be able to include it in the model, and as a result we have to fit the $k_{0}$ parameter for each reaction. The results show that with just one $k_{0}$ for each reaction, we can fit the hardness, calorimetry and volume fraction data for all alloys very well. This provides confidence that the treatment is sound.

\section{Appendix: CRSS due to age hardening precipitates}

In the present model (Section 4.2) the strengthening due to age hardening is considered to be proportional to the volume fraction of precipitates formed according to Eq. 15. To determine the proportionality constant we collated yield strength data from the literature for a range of Al-Mg-Si based alloys heat treated to $\mathrm{T} 6$ condition using fast quenching (i.e. with all reaction during the quench being suppressed). The data is mainly from industry handbooks $[55,56,37]$ (the composition is taken as the median composition of the composition range), supplemented by data for very low Si Al-Mg-Si-Mn-Fe alloys from [24]. It was confirmed that with optimised proportionality constant literature data on strength has an excellent linear correlation (correlation coefficient 0.99 ) with predictions from the model in Section 4.2. For further confirmation we have plotted the predicted $y_{\mathrm{hpr}}$ vs the measured strength of the same alloys in Fig. 12, which also contains data on T4 strength (i.e. with co-cluster strengthening). The good linear correlation confirms the present treatment. (The correlation coefficient is 0.98 . It is somewhat lower than that for the full model, which is primarily due to some slight variations in the minor strengthening mechanisms between the alloys.) 


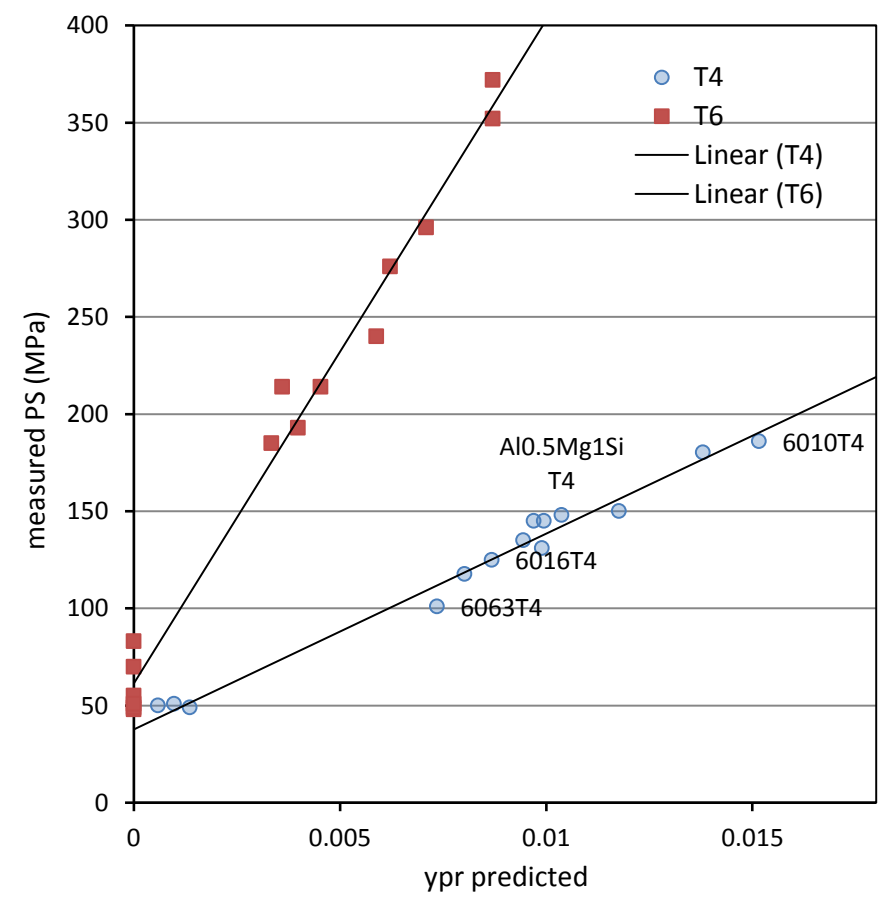

Fig. 12: Yield strength for range of Al-Mg-Si based alloys in T6 and T4 condition, as a function of the total amount of Mg plus Si in either the $\beta^{\prime \prime}$ phase (for the T6 condition) or the co-clusters (for the T4 condition, data from [24]). The alloys include AA6061, AA6063, AA6463, AA6009, AA6010, AA6066, AA6101, and Al-1Mg-0.2Si and Al-1Mg-0.2Si-0.2Cu. Also included are O temper data for AA6061 and AA6063.

\section{Summary}

In this work, we introduce a new physically-based model that allows to predict the quench sensitivity for the technologically important step of cooling from solution annealing during the age hardening procedure of Al-Mg-Si alloys. The model predicts the volume fraction of precipitates formed with the corresponding enthalpy changes, and both yield strength and hardness in the quenched and in the quenched + aged condition are predicted. For its setup, the model combines the latest findings in modelling of diffusion controlled phase transformations and in modelling of the thermodynamics of technically important complex alloy systems, including first principles modelling. For the set-up and testing of the model, we considered an extensive set of experimental results from Differential Scanning Calorimetry, optical and electron microscopy as well as X-ray diffraction. All together more than 1000 data points are taken into account. The model considers two consecutive precipitation reactions during cooling: $\beta-\mathrm{Mg}_{2} \mathrm{Si}$ and $\mathrm{B}^{\prime}$. Comparing the experimental results in a very wide dynamic range of about 
0.05 to $2 \cdot 10^{4} \mathrm{~K} / \mathrm{min}$ for enthalpy change, $\mathrm{Mg}_{2} \mathrm{Si}$ volume fractions and $\mathrm{T} 6$ hardness the model delivers generally excellent fits. Application of the model will help to optimise the exploitation of the age hardening potential of the widely used Al-Mg-Si alloys. For instance the model allows to predict the critical cooling rate of a certain alloy composition - this helps to design an appropriate cooling process for the heat treatment shop. Or, being fixed to a certain cooling method in industrial plants, one could choose the optimal alloy composition. Implementing the model in FEM tools and simulating the cooling process moreover will allow to predict the mechanical properties of complex components at every location.

\section{Acknowledgements}

Most of the experiments were performed by several experimentalists. The following persons are acknowledged for performing DSC experiments at the University of Rostock: R. Steuer, M. Beck and C. Fabry. We gratefully thank $\mathrm{O}$. Kessler and $\mathrm{C}$. Schick for the fruitful discussions of the DSC work. For performing SEM and TEM experiments M. Dammer, D. Hasselfeldt, M. Beck (all University of Rostock), Dr. N. Wanderka (Helmholtz Zentrum Berlin); Dr. P. Rometsch (formerly University of Southampton, now Monash University) and Dr. S. Wang (University of Southampton) are acknowledged. Aleris and British Aluminium are acknowledged for supplying selected alloys. BM is on sabbatical at the University of Southampton supported by a fellowship within the Postdoc-Program of the German Academic Exchange Service (DAAD). BM gratefully acknowledges this support.

\section{References}

[1] Polmear IJ. Light alloys, 4th ed., Butterworth-Heinemann, Oxford, 2006.

[2] Rometsch PA, Starink MJ, Gregson PJ. Improvements in quench factor modelling, Mater. Sci. Eng. A 339 (2003) 255-264.

[3] Deschamps A, Texier G, Ringeval S, Delfaut-Durut L. Influence of cooling rate on the precipitation microstructure in a medium strength Al-Zn-Mg alloy, Mater. Sci. Eng. A 501 (2009) 133-139.

[4] Zhang Y, Milkereit B, Kessler O, Schick C, Rometsch PA. Development of continuous cooling precipitation diagrams for aluminium alloys AA7150 and AA7020, J. Alloy. Compd. 584 (2014) $581-$ 589.

[5] Cavazos JL, Colas R. Precipitation in a heat-treatable aluminum alloy cooled at different rates, Mater. Charact. 47 (2001) 175-179.

[6] Cavazos JL, Colas R. Quench sensitivity of a heat treatable aluminum alloy, Mater. Sci. Eng. A 363 (2003) 171-178.

[7] Milkereit B, Wanderka N, Schick C, Kessler O. Continuous cooling precipitation diagrams of Al-MgSi alloys, Mater. Sci. Eng. A 550 (2012) 87-96.

[8] Rometsch PA, Zhang Y, Knight S. Heat treatment of 7xxx series aluminium alloys - Some recent developments, Trans. Nonferrous Met. Soc. China 24 (2014) 2003-2017.

[9] Tiryakioğlu M, Robinson JS, Eason PD. On the quench sensitivity of 7010 aluminum alloy forgings in the overaged condition, Mater. Sci. Eng. A 618 (2014) 22-28. 
[10] Morgeneyer TF, Starink MJ, Wang SC, Sinclair I. Quench sensitivity of toughness in an Al alloy: Direct observation and analysis of failure initiation at the precipitate-free zone, Acta Mater. 56 (2008) 2872-2884.

[11] Hoffmann F, Kessler O, Lübben T, Mayr P. "Distortion Engineering" - Distortion control during the production process, Heat Treat. of Met. 31 (2004) 27-30.

[12] Reich M, Kessler O. Mechanical properties of undercooled aluminium alloys and their implementation in quenching simulation, Mater. Sci. Technol. 28 (2012) 769-772.

[13] Rose A, Kessler O, Hoffmann F, Zoch HW. Quenching Distortion of Aluminium Castings Improvement by Gas Cooling, Materialwiss. Werkstofft. 37 (2006) 116-121.

[14] Starink MJ. Analysis of aluminium based alloys by catorimetry, Int. Mater. Rev. 49 (2004) 191226.

[15] Birol Y. DSC analysis of the precipitation reaction in AA6005 alloy, Journal of Thermal Analysis and Calorimetry 93 (2008) 977-981.

[16] Esmaeili S, Wang X, Lloyd DJ, Poole WJ. On the precipitation-hardening behavior of the Al-MgSi-Cu, Metall. Mater. Trans. A-Phys. Metall. Mater. Sci. 34A (2003) 751-763.

[17] Esmaeili S, Lloyd DJ. Characterization of the evolution of the volume fraction of precipitates in aged AlMgSiCu alloys using DSC technique, Mater Charact 55 (2005) 307-319.

[18] Milkereit B, Kessler O, Schick C. Recording of continuous cooling precipitation diagrams of aluminium alloys, Thermochim. Acta 492 (2009) 73-78.

[19] Milkereit B, Beck M, Reich M, Kessler O, Schick C. Precipitation kinetics of an aluminium alloy during Newtonian cooling simulated in a differential scanning calorimeter, Thermochim. Acta 522 (2011) 86-95.

[20] Zohrabyan D, Milkereit B, Kessler O, Schick C. Precipitation enthalpy during cooling of aluminum alloys obtained from calorimetric reheating experiments, Thermochim. Acta 529 (2012) 51-58.

[21] Milkereit B, Giersberg L, Kessler O, Schick C. Isothermal Time-Temperature-Precipitation Diagram for an Aluminum Alloy 6005A by In Situ DSC Experiments, Materials 7 (2014) 2631-2649.

[22] Povoden-Karadeniz E, Lang P, Warczok P, Falahati A, Jun W, Kozeschnik E. CALPHAD modeling of metastable phases in the Al-Mg-Si system, Calphad 43 (2013) 94-104.

[23] Starink MJ. A new model for diffusion-controlled precipitation reactions using the extended volume concept, Thermochim. Acta 596 (2014) 109-119.

[24] Starink MJ, Cao LF, Rometsch PA. A model for the thermodynamics of and strengthening due to co-clusters in Al-Mg-Si-based alloys, Acta Mater. 60 (2012) 4194-4207.

[25] Milkereit B, Jonas L, Schick C, Kessler O. Das kontinuierliche Zeit-Temperatur-AusscheidungsDiagramm einer Aluminiumlegierung EN AW-6005A, HTM J. Heat Treat. and Mater. 65 (2010) 159171.

[26] Schumann H. Metallographie, 13th ed., Deutscher Verlag für Grundstoffindustrie, Leipzig, 1991.

[27] Edwards GA, Stiller K, Dunlop GL, Couper MJ. The precipitation sequence in Al-Mg-Si alloys, Acta Mater. 46 (1998) 3893-3904.

[28] Dumolt SD, Laughlin DE, Williams JC. Formation of a modified beta'-phase in aluminum alloy 6061, Scr. Metall. 18 (1984) 1347-1350.

[29] JCPDS. Powder diffraction file PDF-2 database sets 1-47, International Centre for Diffraction Data ., 1993.

[30] Zhang Y, Bettles C, Rometsch PA. Effect of recrystallisation on Al3Zr dispersoid behaviour in thick plates of aluminium alloy AA7150, J Mater Sci 49 (2014) 1709-1715.

[31] Starink MJ, Zahra AM. Kinetics of isothermal and non-isothermal precipitation in an Al - 6 at.\% Si alloy, Philos. Mag. A-Phys. Condens. Matter Struct. Defect Mech. Prop. 77 (1998) 187-199.

[32] Starink MJ. On the meaning of the impingement parameter in kinetic equations for nucleation and growth reactions, J Mater Sci 36 (2001) 4433-4441.

[33] Kampmann R, Wagner R. Kinetics of precipitation in metastable binary alloys -theory and application to $\mathrm{Cu}-1.9$ at \% Ti and Ni-14 at \% Al, in: M.F. Ashby, P. Haasen, V. Gerold, R. Wagner 
(Eds.), Decomposition of Alloys: Proceedings of the 2nd Acta-Scripta Metallurgica Conference, Pergamon Press, 1984, pp. 91-103.

[34] R. H. Brown, L. A. Willey (Eds.). Aluminum: Properties, Physical Metallurgy and Phase Diagrams, ASM International, Metals Park, Ohio, 1967.

[35] Starink MJ, Wang SC. The thermodynamics of and strengthening due to co-clusters, Acta Mater. 57 (2009) 2376-2389.

[36] Li X, Starink MJ. Effect of compositional variations on characteristics of coarse intermetallic particles in overaged 7000 aluminium alloys, Mater. Sci. Technol. 17 (2001) 1324-1328.

[37] Hatch JE. Aluminum, American Society for Metals, Metals Park, Ohio, 1984.

[38] Hsu C, O'Reilly, K. A. Q., Cantor B, Hamerton R. Non-equilibrium reactions in 6xxx series Al alloys, RQ10, Tenth International Conference on Rapidly Quenched and Metastable Materials 304306 (2001) 119-124.

[39] Belov NA, Eskin DG, Aksenov AA. Multicomponent phase diagrams, 1st ed, Elsevier, Amsterdam, Boston, 2005.

[40] Verma A, Kumar S, Grant PS, O'Reilly, K. A. Q. Influence of cooling rate on the Fe intermetallic formation in an AA6063 Al alloy, J. Alloy. Compd. 555 (2013) 274-282.

[41] Starink MJ, Deschamps A, Wang SC. The strength of friction stir welded and friction stir processed aluminium alloys, Scr. Mater. 58 (2008) 377-382.

[42] Bardel D, Perez M, Nelias D, Deschamps A, Hutchinson CR, Maisonnette D et al. Coupled precipitation and yield strength modelling for non-isothermal treatments of a 6061 aluminium alloy, Acta Materialia 62 (2014) 129-140.

[43] Ehlers, F. J. H., Dumoulin S, Holmestad R. 3D modelling of $\beta^{\prime}$ ' $^{\prime}$ in Al - Mg - Si: Towards an atomistic level ab initio based examination of a full precipitate enclosed in a host lattice, Comput. Mater. Sci. 91 (2014) 200-210.

[44] Midling OT, Grong $\varnothing$. A process model for friction welding of Al $\cdot \mathrm{Mg} \cdot \mathrm{Si}$ alloys and $\mathrm{Al} \cdot \mathrm{SiC}$ metal matrix composites - II. Haz microstructure and strength evolution, Acta Metall. et Mater. 42 (1994) 1611-1622.

[45] D. G. Morris. Strengthening Mechanisms in Nanocrystalline Materials, in: S.H. Whang (Ed.), Nanostructured metals and alloys: Processing, microstructure, mechanical properties and applications, Woodhead Pub., Cambridge, U.K., 2011.

[46] Starink MJ, Wang P, Sinclair I, Gregson PJ. Microstructure and strengthening of Al-Li-Cu-Mg alloys and MMCS: II. Modelling of yield strength, Acta Mater. 47 (1999) 3855-3868.

[47] Zhu Z, Starink MJ. Age hardening and softening in cold-rolled Al-Mg-Mn alloys with up to 0.4wt\% Cu, Mater. Sci. Eng. A 489 (2008) 138-149.

[48] A. Kelly, R. B. Nicholson (Eds.). Strengthening Methods in Crystals, Elsevier, London, 1971.

[49] Hansen $N$. The effect of grain size and strain on the tensile flow stress of aluminium at room temperature, Acta Metall. 25 (1977) 863-869.

[50] Chawla KK. Composite materials, 3rd ed., Springer, New York, London, 2009.

[51] Ramakrishnan N. An analytical study on strengthening of particulate reinforced metal matrix composites, Acta Mater. 44 (1996) 69-77.

[52] Zhang $Q$, Chen DL. A model for predicting the particle size dependence of the low cycle fatigue life in discontinuously reinforced MMCs, Scr. Mater. 51 (2004) 863-867.

[53] Ashby MF. Work hardening of dispersion-hardened crystals, Philos. Mag. 14 (1966) 1157-1178.

[54] Kamp N, Sinclair I, Starink MJ. Toughness-strength relations in the overaged 7449 Al-based alloy, Metall. Mater. Trans. A-Phys. Metall. Mater. Sci. 33 (2002) 1125-1136.

[55] Kaufman JG. Introduction to aluminum alloys and tempers, ASM International, Materials Park, $\mathrm{OH}, 2000$.

[56] ASM-International (Ed.). ASM speciality handbook aluminum and aluminum alloys, Materials Park, OH, USA, 1993.

[57] Rothman SJ, Peterson NL, Nowicki LJ, Robinson LC. Tracer Diffusion of Magnesium in Aluminum Single Crystals, phys. stat. sol. (b) 63 (1974) K29.

[58] Fujikawa S. Tracer diffusion of magnesium in Pseudo-Binary Al-Mg2Si alloys, in: Defect and Diffusion Forum 143-147, 1997, pp. 403-408. 
[59] Landolt-Börnstein. Thermodynamic Properties · Ternary Alloy Systems, Springer-Verlag, 2005.

[60] Yaws CL. Thermophysical properties of chemicals and hydrocarbons, Second edition, Elsevier, Amsterdam, 2014.

[61] Clausen B, Lorentzen T, Leffers T. Self-consistent modelling of the plastic deformation of f.c.c. polycrystals and its implications for diffraction measurements of internal stresses, Acta Mater. 46 (1998) 3087-3098.

[62] Qiao XG, Starink MJ, Gao N. The influence of indenter tip rounding on the indentation size effect, Acta Mater. 58 (2010) 3690-3700.

[63] Wang SC, Zhu Z, Starink MJ. Estimation of dislocation densities in cold rolled Al-Mg-Cu-Mn alloys by combination of yield strength data, EBSD and strength models, J Microsc. 217 (2005) 174178.

[64] Zhu Z, Starink MJ. Solution strengthening and age hardening capability of Al-Mg-Mn alloys with small additions of $\mathrm{Cu}$, Mater. Sci. Eng. A 488 (2008) 125-133.

[65] Totemeier TC, Wright RN, Swank W. FeAl and Mo-Si-B intermetallic coatings prepared by thermal spraying, Intermetallics 12 (2004) 1335-1344.

[66] Zajac S, Bengtsson B, Johansson A, Gullman LO. Optimisation of Mg2Si phase for extrudability of AA 6063 and AA 6005 alloys, Mater. Sci. Forum 217-222 (1996, 217-222) 397-402.

[67] Zajac S, Bengtsson B, Jönsson C, Isaksson A. Quench sensitivity of 6063 and 6082 aluminium alloys, in: 7th International Aluminum Extrusion Technology Seminar, Chicago, 2000, pp. 73-82.

[68] Zajac S, Bengtsson B, Jönsson C. Influence of Cooling after Homogenisation and Reheating to Extrusion on Extrudability and Final Properties of AA 6063 and AA6082 Alloys, Mater. Sci. Forum 396-402 (2002) 399-404.

[69] Cayron C, Buffat PA. Transmission electron microscopy study of the beta ' phase (Al-Mg-Si alloys) and QC phase (Al-Cu-Mg-Si alloys), Acta Mater. 48 (2000) 2639-2653.

[70] Cayron C, Sagalowicz L, Beffort O, Buffat PA. Structural phase transition in Al-Cu-Mg-Si alloys by transmission electron microscopy study on an Al-4 wt\% Cu-1 wt\% Mg-Ag alloy reinforced by SiC particles, Philos. Mag. A-Phys. Condens. Matter Struct. Defect Mech. Prop. 79 (1999) 2833-2851.

[71] Jacobs $\mathrm{MH}$. Structure of metastable precipitates formed during aging of anAl-Mg-Si alloy, Philos. Mag. 26 (1972) 1-13.

[72] Marioara CD, Andersen SJ, Stene TN, Hasting H, Walmsley J, Van Helvoort, A. T. J. et al. The effect of Cu on precipitation in Al-Mg-Si alloys, Philos. Mag. 87 (2007) 3385-3413.

[73] Starink MJ. Analysis of nucleation and growth with the model for diffusion-controlled precipitation reactions based on the extended volume concept, J. Alloys Comp. 630 (2015) 250255. 